\title{
38. MILANKOVITCH PALEOCEANOGRAPHIC CYCLES IN GEOPHYSICAL LOGS FROM ODP LEG 105, LABRADOR SEA AND BAFFIN BAY1
}

\author{
Richard D. Jarrard ${ }^{2}$ and Michael A. Arthur ${ }^{3}$
}

\begin{abstract}
Ocean Drilling Program (ODP) Sites 645 and 646, in Baffin Bay and the Labrador Sea, respectively, were logged following drilling during Leg 105. Geophysical logs in ODP drill sites yield long, continuous records of sedimentary sequences and thus provide the opportunity for examining evidence of periodicity in the Milankovitch band. Such logging records are extremely valuable where core recovery is incomplete and/or where cyclicity is on a scale larger than the length of a core $(<1$ cycle $/ 9.5 \mathrm{~m}$ ), making recognition of cyclicity difficult on the basis of core description or carbonate data. Because these logs are continuous, they can be treated statistically with spectral techniques to enhance understanding of cyclic processes. Because these logs also indicate lithology, they can be readily interpreted in light of available sedimentary and geochemical analyses on any cores.

The interval 288-455 mbsf of Site 645 was logged with sonic, resistivity, and gamma-ray tools. This zone corresponds to an estimated time interval of 1.9-3.1 Ma. These logs exhibit strong cyclicity throughout, which is mainly controlled by variations in porosity. The high sedimentation rate, which permits a vertical resolution of about $5 \mathrm{k} . \mathrm{y}$. for sonic and $17 \mathrm{k} . \mathrm{y}$. for resistivity logs, allows detection of cycle frequencies that correspond to a dominant 100-k.y. period and subordinate $\sim 40-\mathrm{k} . \mathrm{y}$. periodicity in the upper part of the logged interval and perhaps to an increasingly important $\sim 20-\mathrm{k} . \mathrm{y}$. period in the lower interval. The cycles most likely correspond to variations in flux of ice-rafted debris and/or to variations in activity of bottom currents. The patterns suggest waning influence of precession and increasing importance of obliquity as glaciation progressed in the Baffin Bay region.

At Site 646 , the openhole interval of $210-737$ mbsf was logged with neutron, spectral-gamma-ray, gamma-spectroscopy, sonic, and resistivity tools. This interval corresponds in time to $~ 8.5-2.1 \mathrm{Ma}$. Because of variations in sedimentation rate downhole (average $90 \mathrm{~m} / \mathrm{m} . \mathrm{y}$.), the time resolution of logs varies somewhat. In general, variance is strongest in the eccentricity ( $\sim 100$ k.y.) and obliquity ( $\sim 41 \mathrm{k.y}$.$) bands, but vertical resolution limits our ability to resolve frequen-$ cies corresponding to precession, if present. Again, the variation is largely in porosity, which apparently is directly related to variations in clay content. The cycles, which are alternations between clay-rich and coarser-grained sediment, most likely reflect orbital control on changes in intensity of bottom currents. Log responses indicate that significant increases in the intensity of bottom-current activity on Eirik Ridge occurred at about 5.4-5.5 Ma and 4.1-4.2 Ma. A third sedimentary change occurred at about $3.4 \mathrm{Ma}$, causing a major shift in the porosity baseline and character of log cycles and corresponding to both the onset of biogenic silica sedimentation and a substantial increase in sedimentation rate.
\end{abstract}

\section{INTRODUCTION}

Changes in the earth's orbital parameters are now recognized as an important cause of cyclical variations in global and regional climate and oceanographic processes. The periods of eccentricity $(95,000-123,000$ and $413,000 \mathrm{yr})$, obliquity $(41,000$ yr), and precession (19,000-23,000 yr) have been observed in a variety of sedimentary sequences. These "Milankovitch periods" most often have been detected in Pleistocene deep-sea sediments (e.g., Hays et al., 1976; Imbrie et al., 1984; Ruddiman et al., 1986) because of the combination of very strong glacial/interglacial climatic fluctuations and high-resolution dating. The climatic influence of these cycles does not appear to be confined to either the Pleistocene or deep-sea sediments, as illustrated by detection of Milankovitch frequencies in Cretaceous chalk/shale sequences (Arthur et al., 1984, 1986; Fischer and Schwarzacher, 1984) and Triassic lake sediments (Olsen, 1986).

The parameters most frequently used for detection of $\mathrm{Mi}$ lankovitch frequencies in pelagic deep-sea sediments are calcium carbonate concentration (an indicator of the balance between paleoproductivity, dissolution, and/or dilution by other

\footnotetext{
${ }^{1}$ Srivastava, S. P., Arthur, M., Clement, B., et al., 1989. Proc. ODP, Sci. Results, 105: College Station, TX (Ocean Drilling Program).

2 Lamont-Doherty Geological Observatory of Columbia University, Palisades, N.Y. 10964.

3 Graduate School of Oceanography, University of Rhode Island, Narragansett, RI 02882 .
}

components) and $\delta^{18} \mathrm{O}$ of biogenic carbonate (an indicator of ice volume and paleotemperature). However, many other types of sedimentary response to Milankovitch forcing are possible (Fig. 1). Sedimentary responses can be expected to differ between regions or even as a function of time at one location. For example, aridity/humidity cycles or variations in either bottomcurrent strength or ice-rafted material may cause detectable fluctuations in clay mineralogy or clay abundance in one region, while cycles of upwelling or surface temperature may cause variations in one or more biogenous components in another region. Thus, a comprehensive analysis of Milankovitch cycles in any sedimentary sequence requires one to determine both mineralogical and porosity abundances throughout the sequence.

Here, we examine the feasibility of using downhole geophysical logs to detect periodic changes in mineralogy or porosity that are associated with orbital changes (Fischer, 1986). We focus on logging and coring results from two sites drilled during Leg 105: Site 645 in Baffin Bay and Site 646 in the Labrador Sea.

Downhole geophysical logging is a routine part of the study of any ODP site with penetration deeper than 400 meters below seafloor (mbsf). Both physical properties (e.g., velocity, porosity, resistivity) and major-element geochemistry can be logged. Measurements are taken every $15 \mathrm{~cm}$ down the borehole; most logging tools have a vertical resolution of about $50 \mathrm{~cm}$.

For detection of Milankovitch frequencies, downhole logs have four principal advantages over core analyses. First, the wide variety of geochemical and physical properties measured makes almost any significant periodic change in mineralogy or 

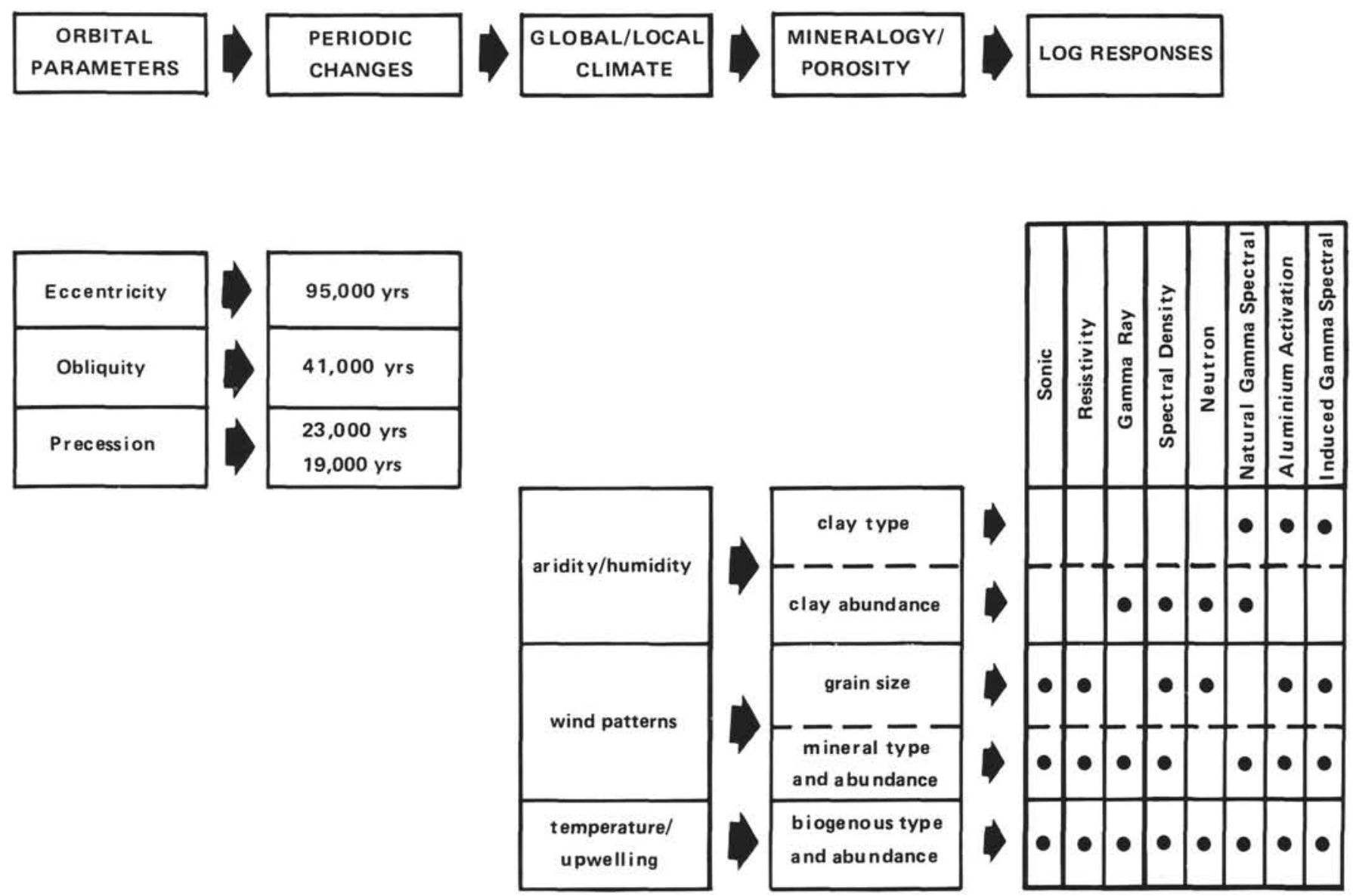

Figure 1. Flow chart of possible climatic effects on geophysical logs. Climatic fluctuations, whether associated with periodic changes in orbital parameters or with local climate, are likely to cause fluctuations in mineralogy or porosity of deep-sea sediments. If so, then these mineralogic or porosity changes are usually detectable in geophysical logs; the affected log depends on the type of mineralogic or porosity change and, therefore, indirectly on the type of climatic change affecting the sediments.

porosity detectable (Fig. 1), if sedimentation rates are high enough to allow resolution of the cycles by the logging tools. Second, logging is much faster than discrete core analyses. Third, and most important, the continuous log measurements are independent of core recovery. The decrease in average ODP core recovery from $94 \%$ in the upper $150 \mathrm{~m}$ of the sediment column to $50 \%-60 \%$ below $200 \mathrm{mbsf}$, associated with the change from hydraulic piston corer to extended-core barrel or rotary corer, is the primary limitation to detection of Milankovitch cycles in pre-Pleistocene ODP cores. Further, core recovery includes both disturbed and undisturbed sediments, with substantial uncertainty in the original depths of undisturbed material. Fourth, identification of cycles in sedimentary sequences is often made visually. If the lithologic expression of such cyclicity is subtle and extends over intervals greater than the length of one core (e.g., $10 \mathrm{~m}$ or more), the cyclicity may not be easily recognized even if core recovery is good.

For detection of Milankovitch frequencies, downhole logs share some of the same limitations as cores and have two unique potential disadvantages. Both cores and logs require good age control for accurate conversion from frequencies in thickness to temporal frequencies. Sometimes cycles in either cores or logs can be caused by autocyclic (local sedimentary) rather than allocyclic (regional climatic or oceanographic) processes. An example of an autocyclic process is turbidite deposition, with a spatial frequency that depends on source supply and source distance and with a temporal frequency that may bear only an indirect relationship to climate. However, this point only em- phasizes the importance of coupling studies of the sediment cores with those of logs. The major limitation to detecting Milankovitch frequencies with logs is that the vertical resolution of logs precludes reliable detection of cycles with wavelengths of less than $2 \mathrm{~m}$. A second limitation is that logs record the indirect effects of climatic change (e.g., mineralogical and porosity changes), rather than the direct effects (e.g., changes in water temperature).

\section{LOG DATA AND SPECTRAL ANALYSIS}

\section{Site 645}

Site 645 was drilled in west central Baffin Bay, between Greenland and Canada. An 1147-m sequence of silty clays and clayey silts was deposited during the last 16-24 Ma. Influx of terrigenous sediment from the surrounding continents was affected locally by contour currents (see Arthur et al., this volume). Onset of major ice rafting, as indicated by a major increase in dropstones, occurs within the interval 340 to $465 \mathrm{mbsf}$ or at about 2.5-3.4 Ma. Only the intervals at 200-243 and 288-455 mbsf, corresponding to $1.3-1.7$ and 1.9-3.1 Ma, respectively, were logged with sonic, resistivity, and gamma-ray tools. The strong similarity in character between sonic and resistivity logs (Fig. 2) indicates that velocity variations are controlled primarily by porosity variations. A strong cyclicity of log responses is present throughout the logged interval. The cycles lack the saw-toothed pattern characteristic of turbidites: gradually upward-decreasing velocity and resistivity, followed by sharp rises. This obser- 


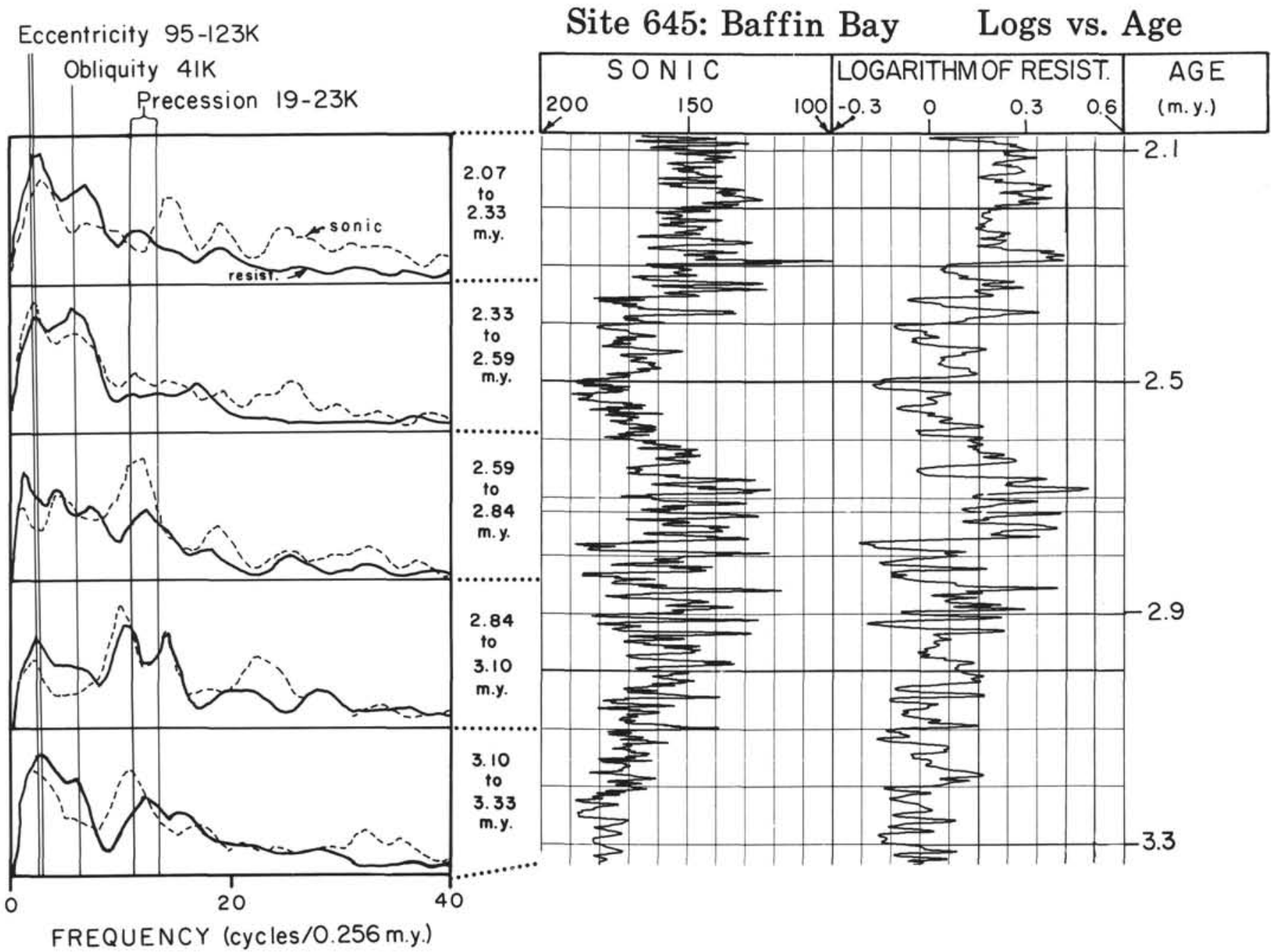

Figure 2. Sonic traveltime (in $\mu \mathrm{s} / \mathrm{ft}$ ) and resistivity logs for a portion of Site 645 , plotted as a function of age. Note the strong periodicity of variations in the logs, shown more quantitatively in the amplitude spectra at left. Superimposed on the amplitude spectra are the predicted locations of amplitude peaks for an association between log cycles and cyclical changes in orbital parameters. Vertical axis of amplitude spectra is percentage of total variance.

vation confirms the sedimentological conclusion (Srivastava, Arthur, et al., 1987a) that few or no recognizable turbidites are present. Possibly because porosity variations in cores are difficult to recognize visually, the cycles picked up by logs were not detected by shipboard sedimentologists. However, an approximately 1- to 2-m cyclicity in color banding was noted in the cores.

The logged interval is almost barren of microfossils, but the combination of sparse micropaleontological control and magnetic reversal stratigraphy allows rather good age control for this interval. Based on the age/depth curve (Srivastava, Arthur, et al., 1987a; using time scale of Berggren et al., 1985), the logs were converted from depth to age (Fig. 2). Note that relative age accuracy is much higher than absolute accuracy. For example, the absolute ages of a log cycle in Figure 2 could be inaccurate by $100,000 \mathrm{yr}$, but the duration of that cycle is unlikely to be inaccurate by more than $15 \%$ (3000 yr for an apparent 20,000 -yr cycle).

Temporal variation in the dominant frequency is obvious in the plots of logs as a function of age. For example, from 2.1 to $2.5 \mathrm{Ma}$, the dominant period of resistivity variations appears to be about $100,000 \mathrm{yr}$ (eccentricity?), whereas from 2.65 to 3.3 $\mathrm{Ma}$, a much higher frequency of about $20,000 \mathrm{yr}$ (precession?) is apparent. Amplitude spectra permit a more detailed examination of the frequency content of the logs. We analyzed the natural logarithm of resistivity, rather than raw resistivity, because resistivity is logarithmically related to porosity. Before spectral analysis of each 512 -point $(0.256$ m.y.) log interval, a first-degree regression trend was removed from the log interval, and the $\log$ interval was standardized. The former procedure removes the dominating zero-order term that would otherwise be present in the amplitude spectrum, associated with the nonzero mean of log data and very gradual trends, such as compaction. Standardization assures numerical stability in the calculation and, more importantly, normalizes the entire spectrum, with the result that the vertical axis of each spectrum is a percentage of total variance. A Hanning filter was applied to each spectrum. Because the vertical resolution of logs is broader than the sample spacing, slight spectral contamination may occur at frequencies near the Nyquist frequency, which is far higher than the frequencies considered here.

Amplitude spectra for five age windows of the sonic and resistivity logs from Site 645 are shown in Figure 2. The same general frequencies are present in all age windows, although the relative magnitudes change through time. In each spectrum, most of the variance is in frequencies of less than 20 cycles per 0.256 
m.y. (periods of greater than $12,000 \mathrm{yr}$ ). As expected with nominal vertical resolutions of about $5000 \mathrm{yr}$ for the sonic log and $17,400 \mathrm{yr}$ for the resistivity log at these sedimentation rates, the amplitude spectra flatten out at very low values for the higher frequencies; thus, the portion of each amplitude spectrum from 40 to 256 cycles per $0.256 \mathrm{~m}$.y. is not shown. Because both sonic velocity and the logarithm of resistivity respond primarily to porosity variations, their amplitude spectra are quite similar in character. The resistivity log has both lower vertical resolution and less high-frequency noise than the sonic log (Fig. 2); thus, the amplitude spectra for the resistivity log have stronger lowfrequency peaks and lower high-frequency tails than the sonic spectra.

For comparison with the observed frequency spectra, we also show in Figure 2 the predicted locations of peaks corresponding to the orbital frequencies of eccentricity $(95,000-123,000 \mathrm{yr})$, obliquity $(41,000 \mathrm{yr})$, and precession $(19,000-23,000 \mathrm{yr})$. In every resistivity spectrum and in most sonic spectra, the largest peak corresponds to the predicted peak location for eccentricity. Peaks in the amplitude spectra are also evident at or near the 41,000 -yr obliquity period and the 19,000 - to 23,000 -yr precession period, with gradual trends of increasing energy in the precession band and decreasing energy associated with obliquity with increasing age. In the interval $2.8-3.1 \mathrm{Ma}$, the portion of the amplitude spectrum tentatively correlated with precession may permit the resolution of both the 19,000- and 23,000-year precession periods.

Differences between observed and predicted locations of peaks can be caused by either sedimentation rate errors or a nonorbital source for the cyclicity. One can distinguish between these two possibilities only when more than one significant peak is present in a spectrum. Slight errors in the assumption of constant sedimentation rate are suggested by small systematic shifts of all observed peaks with respect to predicted peaks within a spectrum. For the 2.8-3.1 Ma interval, observed peaks are centered about $10 \%$ left of predicted peaks, suggesting that the sedimentation rate is about $150 \mathrm{~m} / \mathrm{m} . \mathrm{y}$, rather than $135 \mathrm{~m} / \mathrm{m} . \mathrm{y}$, if we assume that the spectral peaks represent the true periodicities of the orbital parameters. A similar shift to the right in the interval 2.1-2.3 Ma suggests a sedimentation rate of about 120 $\mathrm{m} / \mathrm{m} . \mathrm{y}$.

The cyclical variations of the porosity-sensitive sonic and resistivity logs at Site 645 are correlated with gamma-ray fluctuations as well. Increasing clay content, indicated by high gamma intensities, is associated with higher sonic traveltime (lower velocity) and lower resistivity. We discuss possible causes of these periodic variations in another section.

\section{Site 646}

Site 646 is located in the Labrador Sea, on the Eirik Ridge about $300 \mathrm{~km}$ southwest of the southern tip of Greenland. A $767-\mathrm{m}$ interval of visually monotonous silty clays and clayey silts represents deposition from $8.5 \mathrm{Ma}$ to the present, at an average sedimentation rate of about $90 \mathrm{~m} / \mathrm{m}$.y. Seismic profiles indicate that much of the sedimentary section at Eirik Ridge is composed of drift deposits, with local sediment accumulation rates affected by bottom-current activity. The onset of ice rafting at Site 646 occurs at 236 mbsf, or about $2.5 \mathrm{Ma}$, based on the first occurrence of significant quantities of dropstones (Srivastava, Arthur, et al., 1987b).

Virtually the entire drilled interval (0-750 mbsf) was logged with the neutron, spectral-gamma-ray, and gamma-spectroscopy tools. The openhole interval below pipe (206-737 mbsf) was also logged with the sonic, gamma-ray, and resistivity tools. Here, we focus only on the openhole interval below $210 \mathrm{mbsf}$, because the through-pipe logs show a pronounced $9.5-\mathrm{m}$ cyclicity corresponding to positions of pipe collars; this cyclicity pre- cludes detection of any cyclicity with a 9-m period that might be present (as might be expected for eccentricity at the mean sedimentation rate of $90 \mathrm{~m} / \mathrm{m}$.y.).

Figure 3 shows the sonic and porosity logs for Site 646 . The porosity log is calculated from resistivity, using the Archie equation (Jarrard et al., this volume). This rescaling of the log cannot affect visible cyclicity or amplitude spectra. As at Site 645 , the sonic log exhibits more high-frequency signal due to higher vertical resolution, as well as more high-frequency noise. The quality of both logs is excellent (Srivastava, Arthur, et al., 1987b). Also shown in Figure 3 is a log of modified uranium/ thorium ratio for Site 646. This ratio is sensitive to calcium carbonate percentage (Jarrard et al., this volume); a lower uranium/ thorium ratio corresponds to a higher modified uranium/thorium ratio (0.3-uranium/thorium) and higher calcium carbonate.

As at Site 645, the sonic and transformed resistivity logs show similar small-scale character (Fig. 3) because both properties are primarily controlled by porosity. The gradual compaction trend is more marked on the sonic log. As discussed later, the sudden porosity increase above 340 mbsf is probably caused by the first occurrence of siliceous microfossils, but it is also accompanied by a change in mineralogy (on the basis of interpretation of spectral-gamma and gamma-spectroscopy records; Jarrard et al., this volume) from an average of $65 \%$ clay minerals and $20 \%$ quartz plus feldspar below, to approximately $45 \%$ clay and $45 \%$ quartz plus feldspar above. This change is much more marked on the resistivity log than on the sonic log, because the decrease in velocity from porosity increase is counteracted by an increase in velocity owing to the mineralogic change.

A strong cyclicity is evident throughout all three logs in Figure 3. The dominant period in terms of cycles per meter is clearly not constant throughout the logs; a notable example is the much longer-period variation in the $50 \mathrm{~m}$ above $340 \mathrm{mbsf}$ than in the $50 \mathrm{~m}$ just below that level (Fig. 4). This 340-mbsf change probably corresponds to a change in sedimentation rate. Based primarily on reversal stratigraphy, a sudden doubling of sedimentation rate from about 50 to about $100 \mathrm{~m} / \mathrm{m}$.y. is inferred at this depth (Srivastava, Arthur, et al., 1987b).

Porosity, sonic, and uranium/thorium amplitude spectra for intervals immediately above and below 340 mbsf are shown in Figure 5. For the upper interval, a strong amplitude peak occurs at a frequency of 9 to 11 cycles $/ 78 \mathrm{~m}$, with a much smaller peak at 19 to 20 cycles $/ 78 \mathrm{~m}$. Assuming a sedimentation rate of 95 $\mathrm{m} / \mathrm{m}$.y., the major peak has a temporal period of $85-100 \mathrm{k} . \mathrm{y}$., and the secondary peak has a period of $38-45$ k.y. The amplitude spectrum for the lower interval is similar in character but shifted by approximately a factor of two in frequency, as expected for a constant temporal frequency but halving of sedimentation rate. Again, the dominant period is about $100,000 \mathrm{yr}$, but here, the $\sim 41,000$-yr period is evident only on the sonic spectrum.

The simplest explanation of the velocity and porosity amplitude spectra of Figure 5 is that the patterns result from Milankovitch orbital periods, affected by the vertical resolutions of the tools. The sampling interval for all logs is $15 \mathrm{~cm}$, but the vertical resolution is different: $0.6 \mathrm{~m}$ for the sonic tool and about $1 \mathrm{~m}$ for the resistivity tool. These resolutions correspond to maximum temporal resolutions of 12,000 and $20,000 \mathrm{yr}$ at the $95 \mathrm{~m} / \mathrm{m}$.y. sedimentation rate in the upper interval, and 30,000 and $50,000 \mathrm{yr}$ for the lower sedimentation rate in the lower interval. The 100,000-yr eccentricity cycle should be readily resolvable in both intervals, if present in the sediments; this temporal period is the strongest period in each interval. The 41,000 -yr obliquity period should be readily detectable in the upper interval, but in the lower interval should be barely detectable by the sonic tool and probably undetectable by a resistivityporosity tool. This is exactly the pattern seen in the amplitude 


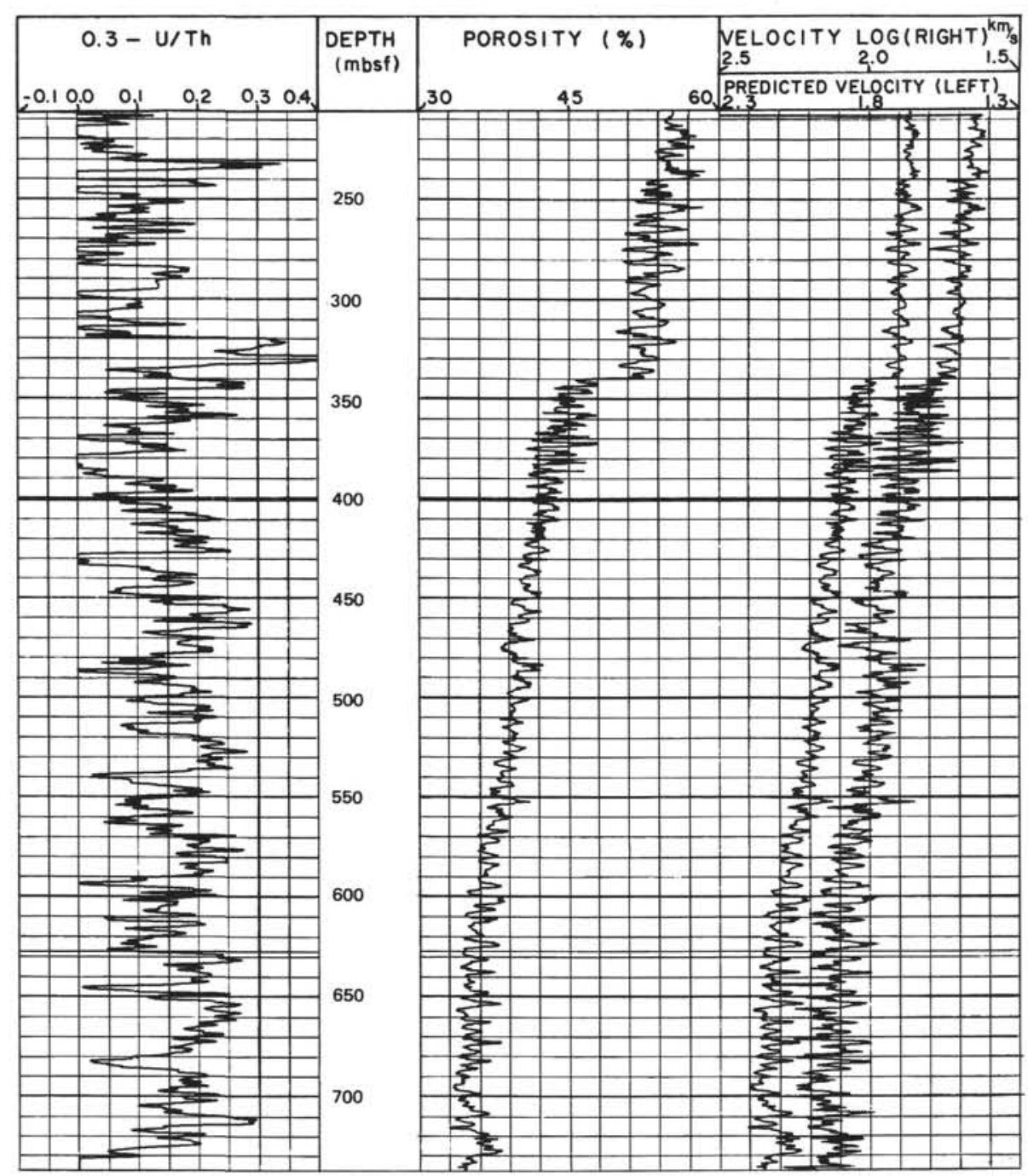

Figure 3. Uranium/thorium, porosity, and velocity $(\mathrm{km} / \mathrm{s})$ logs for the openhole interval of Site 646 . Also shown adjacent to the velocity $\log$ is a predicted velocity $l o g$, based on porosity and Gassmann's theoretical equations (1951). Note that the scale for the predicted velocity log is offset two divisions to the left with respect to the velocity log, to permit comparison despite the near perfect agreement of the logs. Note the high frequency $(6-10 \mathrm{~m})$ cyclicity in porosity and velocity logs and much lower frequency $(50 \mathrm{~m})$ cyclicity in the uranium/thorium log.

spectra. The 19,000 - to 23,000 -yr precession period, if present, should be detectable only by the sonic tool in the upper interval. In fact, it cannot be seen by either log from either interval. Peaks on amplitude spectra are increasingly smeared at higher frequencies by slight sedimentation-rate variations. Thus, we cannot exclude the possibility that a precession signal is present in logs from the upper interval, but we detected none.

The vertical resolution and amplitude spectra for uranium/ thorium are affected less by the vertical resolution of the tool than by noise. We applied a 5-point $(0.76 \mathrm{~m})$ tapered smoothing filter to the log, which led to a nominal maximum temporal resolution of $15,000 \mathrm{yr}$ in the upper interval and $38,000 \mathrm{yr}$ in the lower interval. These nominal vertical resolutions are somewhat further degraded by residual noise. Comparison of the uranium/ thorium ratio, porosity, and velocity amplitude spectra (Fig. 5) shows that the 100,000 -yr period found in the other logs for both depth intervals is present, but reduced in amplitude in the uranium/thorium log. Further, the 41,000 -yr period is detected by the uranium/thoriuim log only in the upper interval, similar to the other logs. In contrast to velocity and porosity, the ura- nium/thorium log is the only log showing a significant long period: a major peak occurs at a period of about $400,000 \mathrm{yr}$, which may be the 413,000-yr eccentricity period.

Paleontology and reversal stratigraphy for this upper interval (260-419 mbsf) of Site 646 cannot determine sedimentation rates precisely. Based on the identification of the peak at 20 cycles $/ 78$ $\mathrm{m}$ as the 41,000 -yr obliquity period for the interval above 340 mbsf (Fig. 5), a sedimentation rate of $95 \mathrm{~m} / \mathrm{m}$.y. is estimated, very near the approximately $100 \mathrm{~m} / \mathrm{m}$.y. sedimentation rate estimated from reversal stratigraphy. For the interval $340-419$ mbsf, we used the identification of peaks at 17 and 22 cycles $/ 78 \mathrm{~m}$ as the 123,000 - and 95,000 -yr eccentricity peaks to refine the sedimentation rates from about $50 \mathrm{~m} / \mathrm{m}$.y. (based on reversal stratigraphy) to $37 \mathrm{~m} / \mathrm{m}$.y.

These two determinations of apparent sedimentation rate are not intended to imply that sedimentation rate was constant throughout an analyzed interval; further, the rate is not necessarily an average rate for the entire interval. Instead, this rate is appropriate for that portion of the log containing most of the amplitude variance. Both the obvious periodicity and peak-to- 


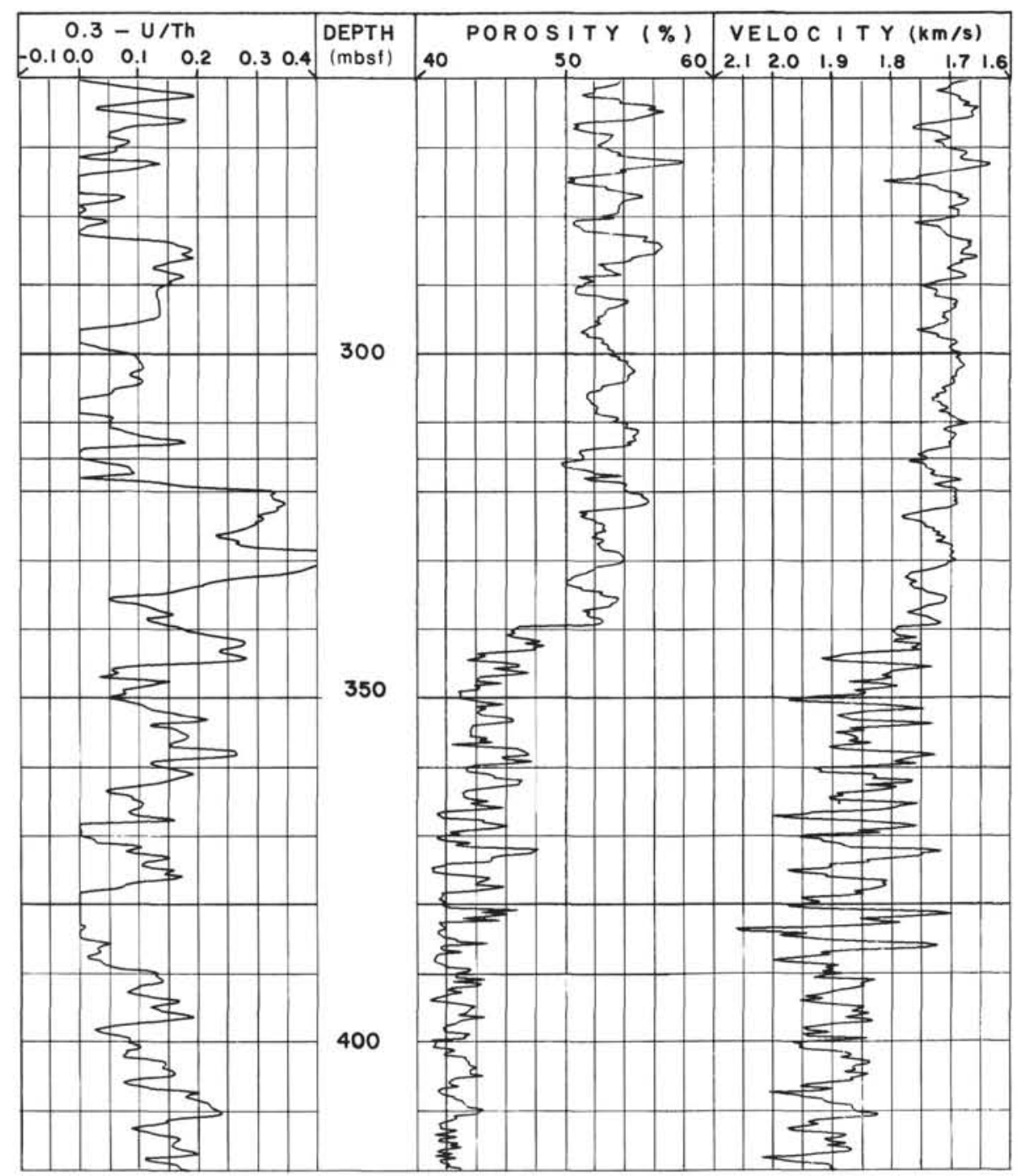

Figure 4. Expanded plot of the upper interval (260.1-418.8 mbsf) of logs shown in Figure 3. Note the major change in cyclicity of porosity and velocity logs at $340 \mathrm{mbsf}$.

trough amplitudes are uniform throughout the interval at 260340 mbsf (Fig. 4); thus, the $95 \mathrm{~m} / \mathrm{m}$.y. sedimentation rate from identification of Milankovitch periods is probably representative of that entire interval. In contrast, peak-to-trough amplitudes for the interval 340-419 mbsf are highest between 367 and $386 \mathrm{mbsf}$ and taper to both sides (Fig. 4). Dividing this interval into two, the amplitude spectra exhibit nearly the same frequency content (Fig. 6). However, examination of the logs (Fig. 4) suggests that the high peak-to-trough amplitudes for 380-388 mbsf dominate the amplitude spectrum for the 380-419 mbsf interval. Below 388 mbsf, the dominant period is much longer, possibly implying more rapid sedimentation rates. Thus, it is incorrect to assume that the $37 \mathrm{~m} / \mathrm{m}$.y. rate is appropriate for the entire depth interval of 340-419 mbsf. Indeed, reversal stratigraphy indicates that average sedimentation rates may be lower just above about $380-400$ mbsf than below that depth (Clement et al., this volume).

Sedimentation rates below about $420 \mathrm{mbsf}$ are uncertain. $\mathrm{Al}$ though the average sedimentation rate of $90 \mathrm{~m} / \mathrm{m}$.y. for all of Site 646 appears to be approximately valid for the lower onehalf of the drilled section, the age data are unable to define the extent of sedimentation-rate changes within this interval (Srivastava, Arthur, et al., 1987b). Figure 7 shows the detailed log variations for the interval at 420.0-731.9 mbsf; the length of this in- terval (2048 points at $15.2-\mathrm{cm}$ sampling) was chosen because spectral analysis uses a number of data points having a power of two. Amplitude spectra for the entire interval indicate no single major peak (Fig. 8). Instead, they indicate that the strong cyclicity evident in Figure 7 has periods of 4 to $11 \mathrm{~m}$. If smaller depth intervals are chosen for spectral analysis (Fig. 8), one can see that the dominant frequency increases with greater depth. This downward increase in frequency may result from a downward decrease in sedimentation rate.

If porosity cycles in this lower interval are caused by Milankovitch orbital cycles, then one can attempt a tentative identification of these periods (Fig. 8). As in the upper interval, the dominant energy in the sonic and porosity logs appears to be at the 95- to 123-k.y. eccentricity period, and the dominant energy in the uranium/thorium log is at much longer periods. The longperiod uranium/thorium variations are not as sharply peaked at about $413,000 \mathrm{yr}$ as in the upper interval. Like the upper interval, a possible 41,000 -yr cycle can be found almost exclusively in the highest resolution log (velocity) and at the highest apparent sedimentation rates (482.3-560.2 mbsf).

Despite the obvious cyclicity in the lower interval, our inability to identify Milankovitch periods confidently underlines two limitations of all analyses of potential Milankovitch periodicities. First, one needs sedimentation rates that (1) are accurate, 
VELOCITY (-) 8 POROSITY(---) LOGS
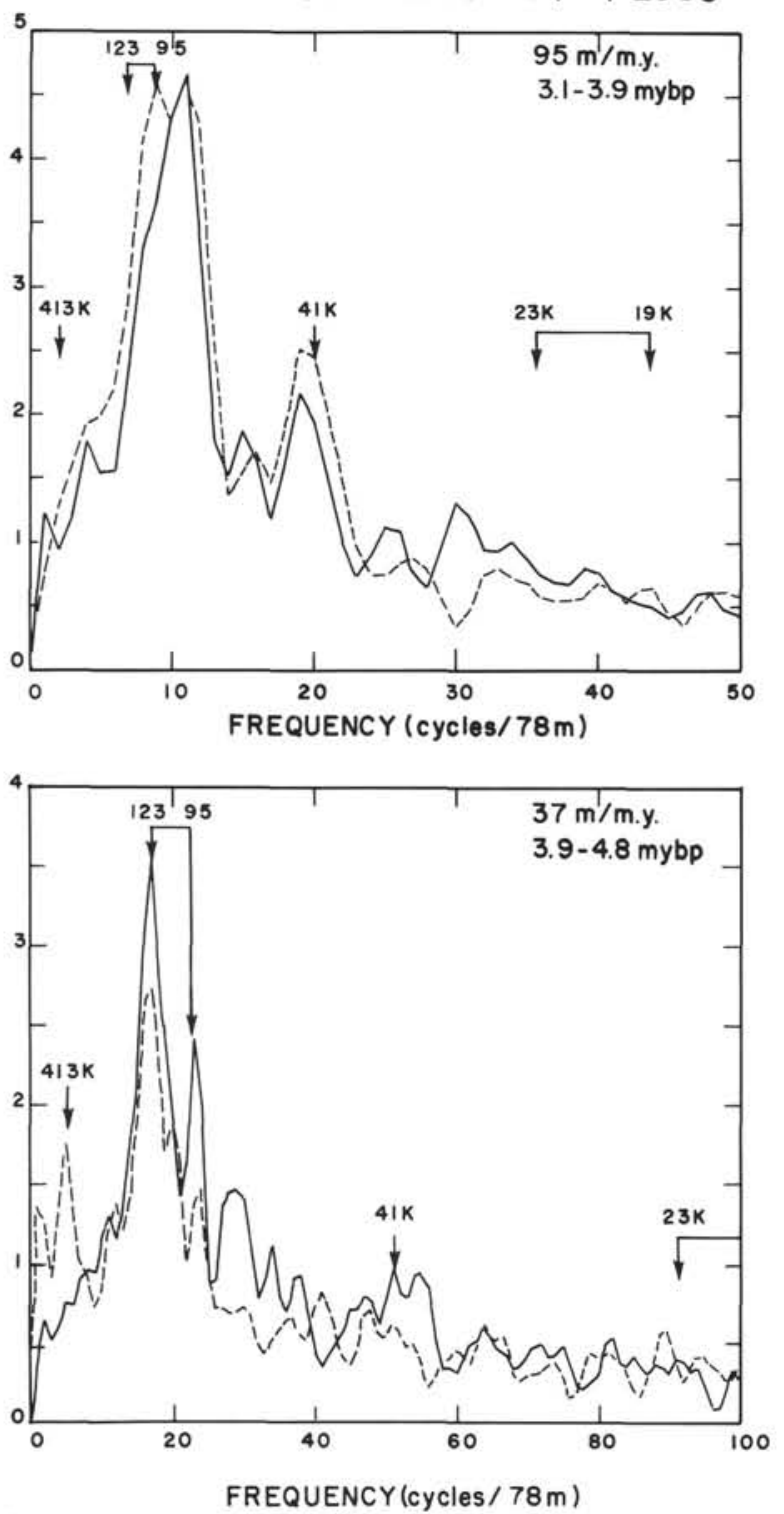

U/Th LOG
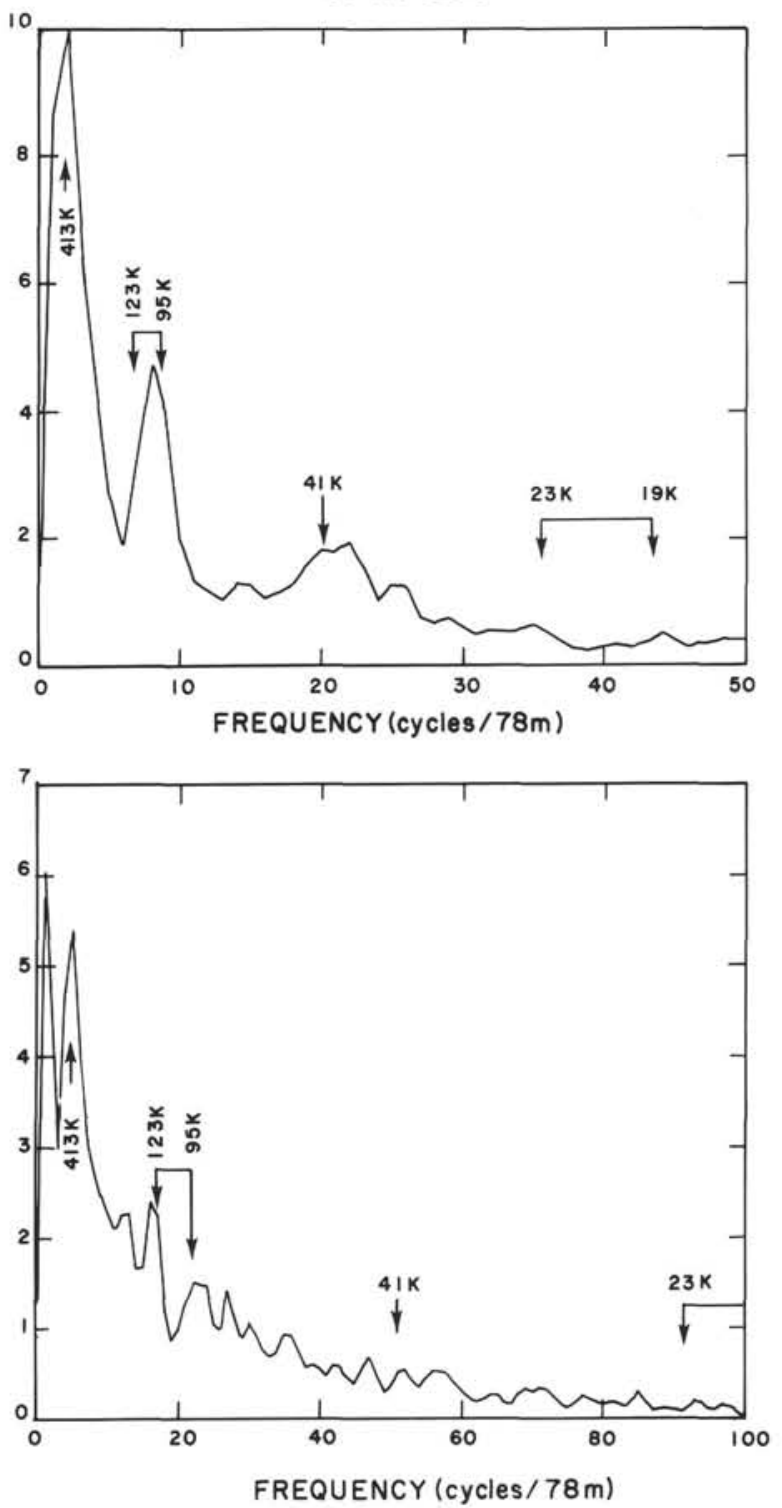

Figure 5. Amplitude spectra for the logs of Figure 4. Top: above $340 \mathrm{mbsf}$; bottom: below $340 \mathrm{mbsf}$. Vertical scale of amplitude spectra is percentage of total variance. Numbers with arrows are the predicted locations of Milankovitch orbital frequencies, assuming the sedimentation rates shown.

(2) persist over a depth interval long enough for spectral analysis, and (3) are independent of the assumption that Milankovitch cycles are present. Second, one must not assume that sedimentation rates are constant throughout an orbital cycle. This assumption is usually invalid, because a change in mineralogy and porosity probably will not occur without an associated change in accumulation rate. For example, the porosity highs in the lower interval are sharper and narrower than the porosity lows (Fig. 7). Nonsymmetrical log cyclicities also can result from nonlinearities in Milankovitch forcing functions. In general, nonsinusoidal cyclicities will cause spectral smearing.

The Site 646 logs present an opportunity to examine a continuous record of changes in cyclicity from about $8.5 \mathrm{Ma}$ to about $2.2 \mathrm{Ma}$ (the bottom of the drill pipe at about $210 \mathrm{mbsf}$ ). Unfortunately, as previously discussed, sedimentation rates are by no means constant throughout the entire interval. Allowing for these variations, some apparent variation in dominance of periodicities can be seen through the section. Variance at the ob- liquity and eccentricity bands in the 3.1 to $4.8 \mathrm{Ma}$ interval is relatively strong in the velocity and porosity logs, whereas the uranium/thorium log indicates strong variance at the longer period of eccentricity ( $413 \mathrm{k.y}$.), with subordinate power in the higherfrequency eccentricity band. Similar results can be obtained for intervals deeper in the hole, for which constraints on sedimentation rates are less reliable. The obliquity period appears in both velocity-porosity and uranium/thorium logs, but not consistently in each interval chosen. Because of the relatively low sedimentation rates $(<50 \mathrm{~m} / \mathrm{m}$.y.) below about $638 \mathrm{mbsf}$ (about $6.8 \mathrm{Ma}$ ) and perhaps between about 340 and 390 mbsf, precessional frequencies are below the resolving power of the logging tools. The average sedimentation rate of $96 \mathrm{~m} / \mathrm{m}$.y. for the remainder of the sequence below 190 mbsf should have allowed resolution of precessional periodicity, yet our spectral analysis detected no definite power in that band. Most of the power is in eccentricity (about 100 k.y.), which is characteristic also of oxygen-isotopic variations for the Quaternary (Imbrie et al., 1984). 

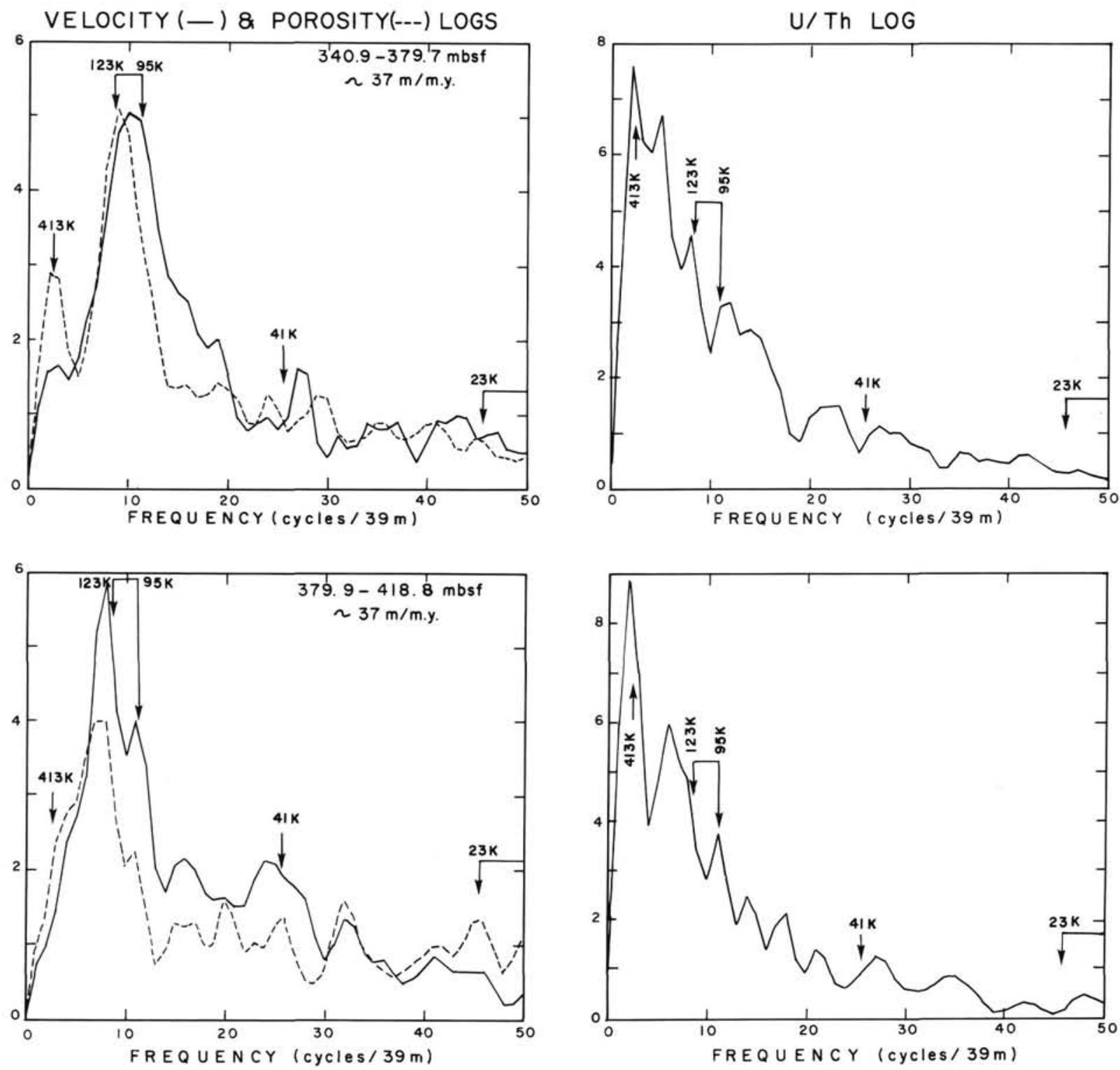

Figure 6. Amplitude spectra for the bottom one-half of the logs shown in Figure 4, divided into two equal depth intervals. Numbers with arrows are the predicted locations of Milankovitch orbital frequencies, assuming a sedimentation rate of $37 \mathrm{~m} / \mathrm{m} . \mathrm{y}$.

\section{Possible Artifacts}

Before interpreting the cyclical behavior of the porosity and velocity logs in terms of paleoclimatic variations, one must consider the possibility that the log cycles are artifacts. Unfortunately, one cannot test their reality by detailed comparison to cores. Poor core recovery below $200 \mathrm{~m}$ at Site 646 precluded any systematic detection of cycles, either visually or geochemically; subtle porosity variations of three porosity units would not be detectable visually or from widely spaced laboratory measurements of porosity. In the interval 343-350 mbsf at Site 646, unusually high core recovery did permit us to undertake densely spaced sampling for analysis of calcium carbonate. These measurements exhibit a good correlation with the porosity log (Fig. 9), showing the same cyclicity as the porosity log. As discussed later, log responses indicate that higher porosity zones are enriched in both calcite and clay minerals.

Two possible artifacts that could cause cyclical log responses are electronic noise and heaving of the ship. We are not aware of electronic noise ever having caused cyclical log response, nor can we conceive of a way that electronic noise might cause similar cyclical behavior in two tools as different in physical principles as sonic and resistivity. The remote possibility of such an artifact can be investigated easily. Electronic noise in most equipment is almost perfectly periodic (e.g., $60 \mathrm{~Hz}$ ), and the constant logging speed should result in a constant periodicity in the logs. Instead, the periodicity in the logs undergoes both gradual (below $430 \mathrm{mbsf}$ ) and sudden ( $340 \mathrm{mbsf}$ ) changes.

Heaving of the ship at up to $10 \mathrm{~m}$ during logging of Site 646, in conjunction with a constant speed of the logging winch, could have caused an irregular speed of the logging tool uphole, conceivably even with occasional slight downward motion. The result would be local stretch and compression of the log, in comparison to the true variation of formation properties with depth. Unlike electronic noise, a ship's heaving has a modulated, timevarying periodicity. During logging of Site 646, a wireline heave compensator was used to reduce the effect of ship's heaving on the logging tool. Analysis of fluctuations in cable tension indi- 


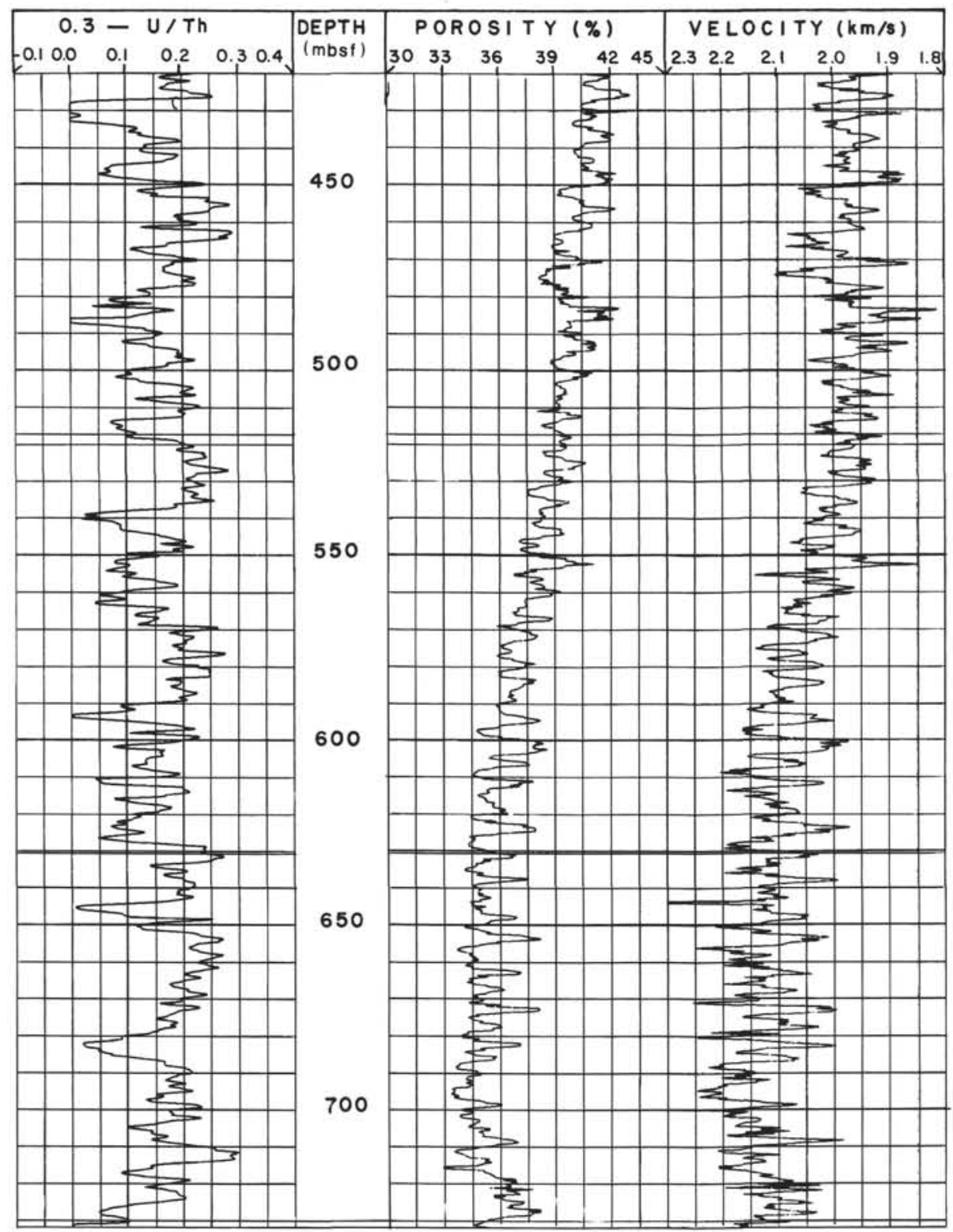

Figure 7. Expanded plot of the lower interval (420.0-731.9 mbsf) of logs shown in Figure 3.

cates that the wireline heave compensator substantially reduces the effect of heaving, but this analysis does not permit an estimate of the effect of residual ship's heaving on the logs. Amplitude spectra of the cable-tension log show that virtually all of the variance in cable tension occurs at frequencies greater than one cycle per meter; these frequencies are higher than the highest frequencies shown in our amplitude spectra, in a near-zero portion of these amplitude spectra.

Note that the sonic and resistivity tools, although on the same tool string, are several meters apart. Thus, they do not log the same depth at the same time. Any effect of heaving or electronic noise on the logs will be simultaneous in time, but several meters offset in depth. For example, residual heaving of the ship would cause the sonic and resistivity logs to record the same subsurface formation boundary at somewhat different apparent depths. Such is not the case at Site 646: the cyclical character changes evident in logs of velocity (from sonic tool) and porosity (from resistivity tool) show a close depth correspondence. Jarrard et al. (this volume) calculated a pseudovelocity log for
Site 646 from porosity and mineralogy, based on Gassmann's equations (1951). This $\log$, shown adjacent to the velocity log in Figure 3 , is virtually identical to the measured velocity $\log$ in both magnitude and fine-scale character, with no depth shifts between the two. Thus, there is no doubt that the porosity and velocity logs reliably indicate real variations in formation properties.

\section{MINERALOGIC AND PALEOCEANOGRAPHIC CAUSES OF CYCLES}

\section{Site 645}

As previously stated, the cyclic fluctuations in velocity, resistivity, and gamma-ray logs over part of the middle to late Pliocene sequence at Site 645 probably do not result from turbidite sedimentation, nor is the biogenic carbonate component significant over this interval (generally less than $15 \%$ ) as a dilutant of clay content. Because porosity appears to be the major variable 

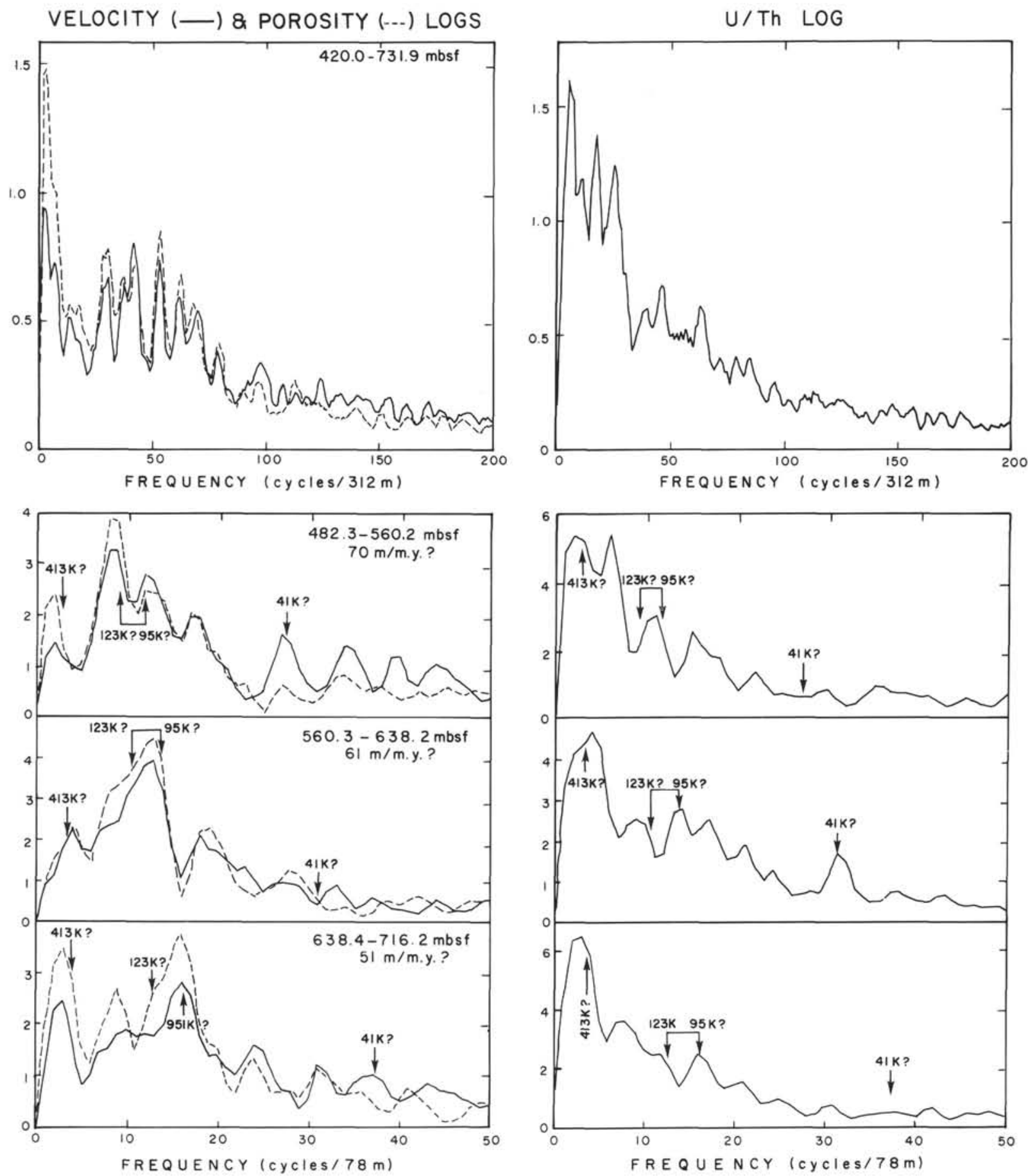

Figure 8. Amplitude spectra for the logs of Figure 7. Spectra at top are for the entire depth interval, and spectra at bottom are for three smaller segments of the depth interval. Numbers with arrows are predicted locations of Milankovitch orbital frequencies, assuming the sedimentation rates shown. Question marks emphasize the uncertainty of sedimentation rates and, therefore, of predicted peak locations.

controlling the resistivity and sonic log response, the most likely explanation of these cycles is that they represent something that controls clay content and/or grain-size sorting. The strong influence of bottom currents was noted in the middle-late Miocene through early Pliocene portion of the sequence at Site 645, on the basis of both seismic characteristics and studies of textures and sedimentary structures (Arthur et al., this volume; Cremer, this volume; Hiscott et al., this volume). Ice-rafted debris is also noted over the Pliocene-Pleistocene portion of the sequence, particularly after about $3.2 \mathrm{Ma}$, with a major increase in sediment flux and dropstone abundance at about 2.6 to 2.5 Ma. Both fluctuating current velocities and variations in ice rafting have the potential to produce cyclic variations in porosity. For example, changes in current strength can produce changes in the relative amounts of finer vs. coarser-grained sediments (fluctuations in clay content), which, in turn, affect porosity. Likewise, ice-rafted debris is commonly poorly sorted and produces less porous deposits than clay-dominated intervals.

We cannot say definitively whether ice rafting or current variations modulated sedimentation at Site 645 . We suggest that 


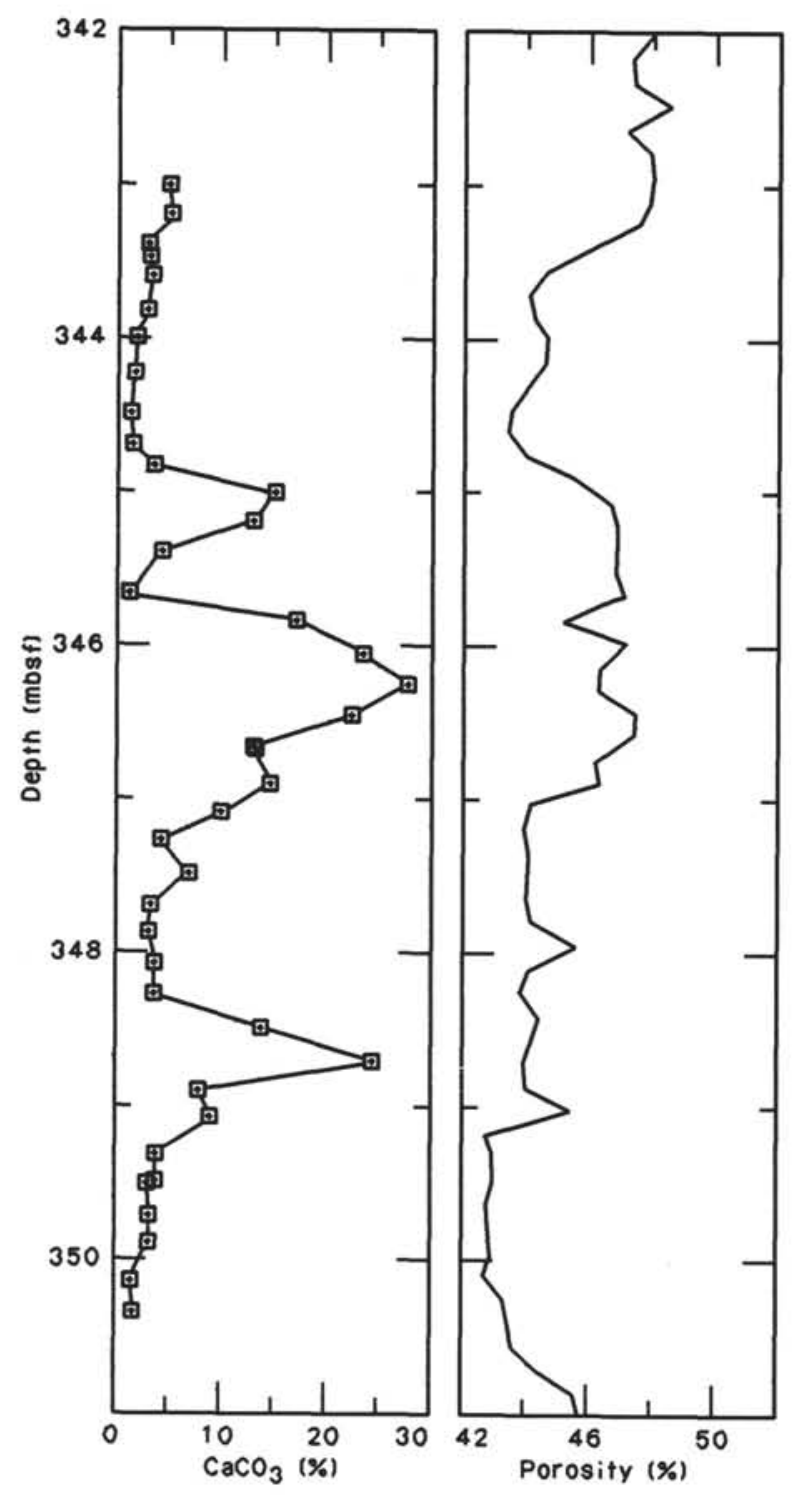

Figure 9. Comparison of porosity log with percentage of calcium carbonate for 343- 351 mbsf at Site 646. Sampling interval for calcium carbonate analyses was $20 \mathrm{~cm}$ for this short interval of good core recovery.

bottom-current fluctuations, perhaps with the overprint of fluctuations in ice-rafted debris, produced the cycles from about 3.3 to $2.6 \mathrm{Ma}$. The currents are attributed to a strong, southerly flowing contour current in western Baffin Bay that may indicate deep convection and formation of dense, cool water that flowed out of Baffin Bay into the Labrador Sea at that time (Arthur et al., this volume). Production of such deep-water masses may have depended on a source of warmer and more saline surface waters flowing into Baffin Bay from the northern Labrador Sea. This source became less important following the climatic deterioration in the Northern Hemisphere at about $2.5 \mathrm{Ma}$. It is interesting that an apparently strong precessional cycle exists over this interval, as we might expect modulation of incursions of warmer Labrador Sea (i.e., subarctic) surface waters by the precessional cycle at this latitude. The decrease in importance of the precession period and increasing strength of the obliquity period at about $2.6 \mathrm{Ma}$ suggests that a different sedimentation regime prevailed, probably one dominated by variations in flux of ice-rafted sediment, largely controlled by obliquity variations.

\section{Site 646}

In this section, we examine the mineralogical and paleoceanographic causes of the porosity variations logged at Site 646 . We begin with the rationale for comparing log-based mineralogy to porosity and the potential impact of mineralogy errors on such comparisons. We then deduce the mineralogical and paleoceanographic factors controlling both cyclical and long-term porosity changes, beginning at the top of the logged interval. This section concludes with comparisons of log-based and seismic stratigraphic interpretations of the bottom-current history of the site, as well as brief speculations on the mechanism of orbital forcing of bottom-current variations.

With no possibility of detecting cycles in cores below 200 mbsf at Site 646 , the sedimentological causes of the cyclical porosity variations must be inferred primarily from other logs. Porosity variations might result directly from grain-size variations within a single mineral component (e.g., quartz) or indirectly from variations in the percentage of minerals of different grain size (e.g., coarse-grained quartz and feldspar vs. fine-grained clay minerals and nannofossils). Jarrard et al. (this volume) calculated approximate mineralogical variations for the interval at 206-737 mbsf, based on inversion of bound-water, potassium, and uranium/thorium logs. Comparison of this continuous estimation of mineral abundance with the porosity log can indicate whether the porosity fluctuations represent mineralogical fluctuations. Figure 10 shows the computed mineralogic column and porosity log for the interval at $260.1-418.8 \mathrm{mbsf}$, whose periodicity is analyzed in Figures 5 and 6. Figure 11 is a similar plot for the interval at $420.0-731.9$ mbsf, whose periodicity is analyzed in Figure 8. Also shown in Figures 10 and 11 is the correlation coefficient of $10-\mathrm{m}$ intervals between the porosity and gamma-ray logs, and between the porosity and biogenousmineral logs.

The techniques, assumptions, and errors associated with mineralogy inversion were described by Doveton (1986). Three limitations of the mineralogy inversion for Site 646 are relevant to subsequent discussions in this section. First, the calculated mineral abundances have a substantially higher noise level than the porosity log, because the noise in three separate logs (each less accurate than resistivity) is compounded. Because raw logs are lower in noise level than computed mineralogy, we chose to determine amplitude spectra from raw logs, such as porosity, rather than from mineralogy logs. Second, the calculated abundances of opal plus calcite are too high, based on comparison to carbonate analyses of cores. This error arises from uncertainty in the uranium/thorium ratios for the different components (Jarrard et al., this volume). However, this does not affect the usefulness of calculated relative abundances of biogenous components as a function of depth, nor does it affect the correlation coefficient of porosity with calculated biogenous component. Third, correlation coefficients for computed clay mineral content vs. porosity are similar in sign, but much lower than those for gamma-ray vs. porosity. This difference implies that the gamma-ray log, which was not used in the inversion, would probably have been superior to the bound-water log, which dominates the solution for clay percentage.

The dominant feature of the upper interval (Fig. 10) is the sudden uphole increase in porosity at $340 \mathrm{mbsf}$. Above this depth, clay content is substantially reduced and the content of quartz plus feldspar almost doubles. As previously discussed, the sedimentation rate at Site 646 doubles at and above 340 mbsf. Because the percentage of clay minerals is halved at this depth, the accumulation rate of clay minerals is approximately constant across the transition. The increase in sedimentation rate is caused by an increase of approximately a factor of four in net accumulation rate of coarse-grained quartz and feldspar; biogenous accumulation rate also increases. 


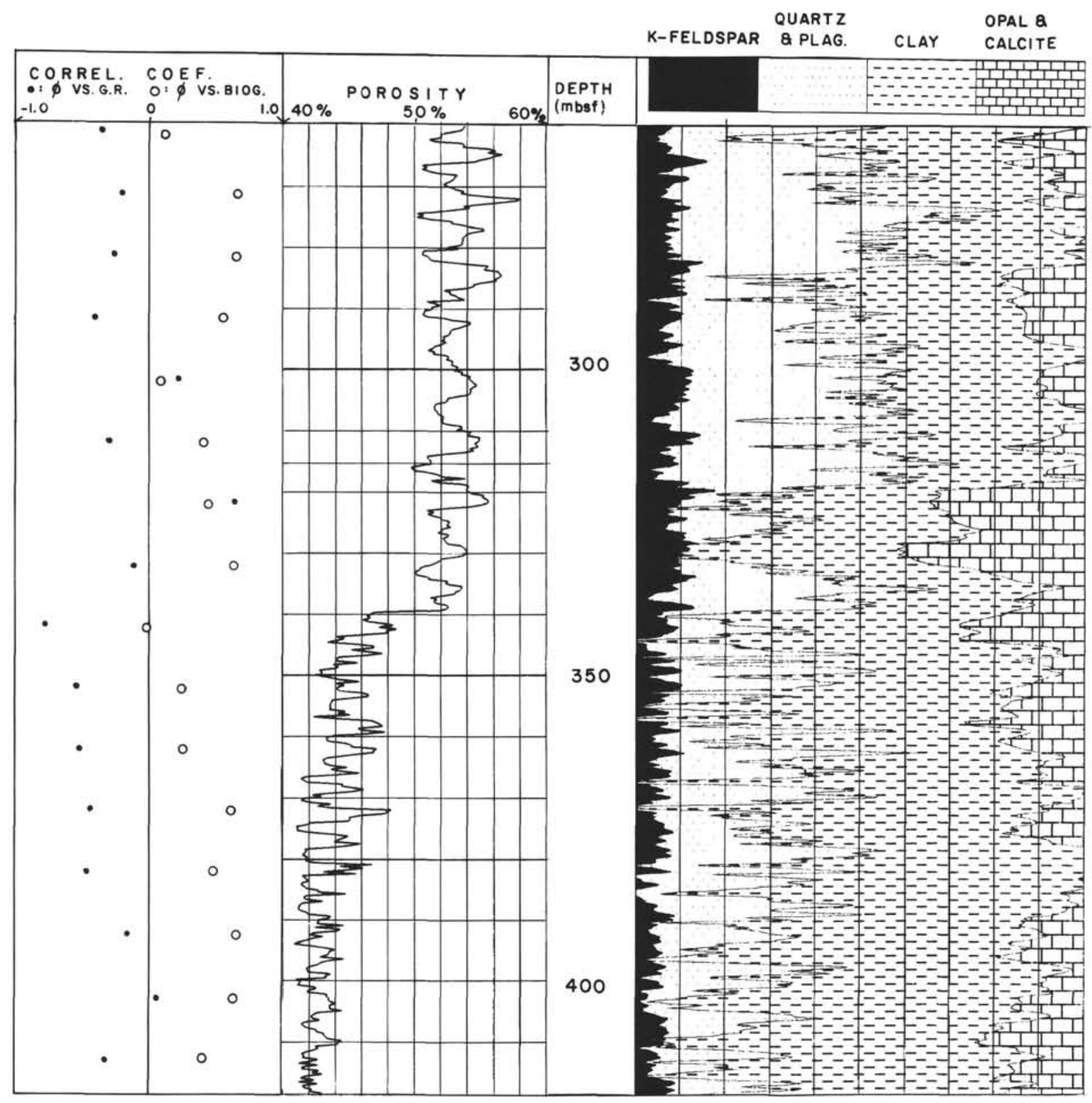

Figure 10. Mineralogic column for the upper interval (260.1-418.8 mbsf) of Site 646, based on log inversion by Jarrard et al. (this volume). Also shown are the porosity log and correlation coefficients for $10-\mathrm{m}$ intervals of porosity vs. biogenous component log and porosity vs. gamma-ray log.

The porosity increase probably occurs in spite of, rather than because of, the decrease in clay content. At depths shallower than 1 to $2 \mathrm{~km}$ below seafloor in most terrigenous sequences, a decrease in clay normally causes a decrease in porosity. The depth of the porosity increase corresponds closely to the $340 \mathrm{mbsf}$ core depth of the first occurrence of siliceous fossils (Srivastava, Arthur, et al., 1987b). Siliceous fossils above $340 \mathrm{mbsf}$ are rarely as high as $10 \%$ by volume, on the basis of smear-slide analysis. This abundance is below the resolving power of the mineralogy inversion, yet high enough to have a substantial porosity effect. An extreme example of the effect of siliceous microfossils on porosity is found at nearby Site 647: a diatom claystone and clayey diatomite unit at $110-230 \mathrm{mbsf}$ has rebound-corrected porosities of $80 \%$ (Srivastava, Arthur, et al., 1987c), 20 porosity units higher than porosities at the top of the underlying clay- stone and 20 to 30 porosity units higher than normal porosities for this sub-bottom depth (Busch, this volume).

The strong cyclicity throughout the upper interval (260.1$418.8 \mathrm{mbsf}$ ), previously discussed in terms of its frequency content, can now be examined in terms of its mineralogical causes and paleoceanographic implications. Excluding ice rafting, which first appears at about 2.5 to $2.6 \mathrm{Ma}(236 \mathrm{mbsf}$ ) at this site, two potential factors exist that could produce this cyclicity: (1) variable productivity superimposed on a relatively constant background clay-mineral flux, and (2) fluctuation in bottom-current velocity and winnowing or transport of the clay fraction. Because waning currents would preferentially allow sedimentation of the clay fraction (coarse-fraction components are minor at this site; Cremer and LaTouche, this volume), cyclic porosity variations might be produced by varying intensity of bottom 


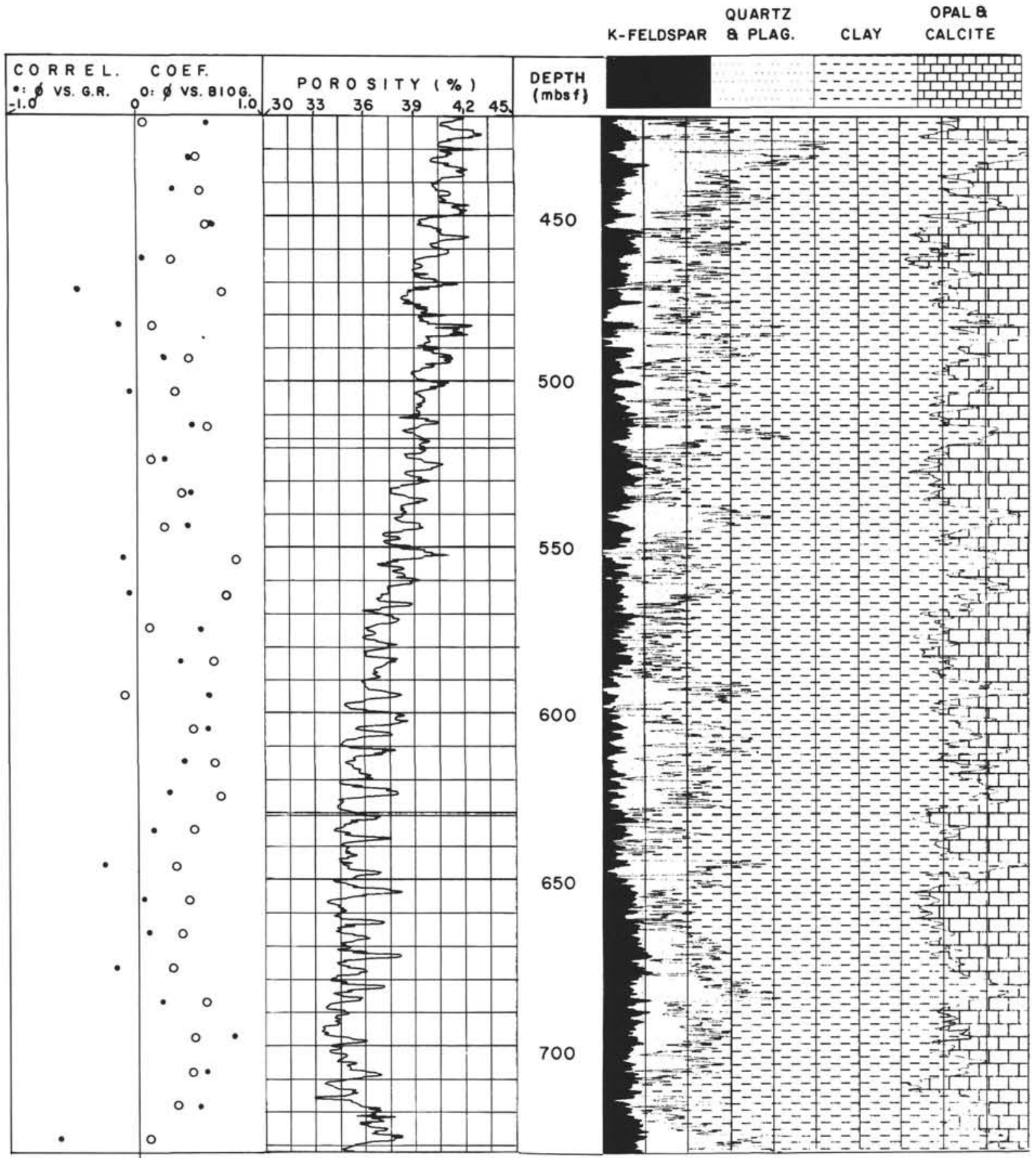

Figure 11. Mineralogic column for the lower interval (420.0-731.9 mbsf) of Site 646, based on log inversion by Jarrard et al. (this volume). Also shown are the porosity log and correlation coefficients for $10-\mathrm{m}$ intervals of porosity vs. biogenous component log and porosity vs. gamma-ray log.

currents. Increasing clay content generally corresponds to increasing porosity. Thus, times of higher current velocity and winnowing presumably would concentrate coarser-grained components (quartz, feldspar, foraminifers, etc.) and produce intervals of better packing and somewhat lower porosity.

Throughout the upper interval of Site 646, porosity is strongly correlated with the percentage of biogenous component (calcite plus opal). A similar correlation can be found between the porosity log and core analyses of calcite, for the short interval in which closely spaced core analyses were possible (Fig. 9). However, the cause of this correlation might change suddenly at 340 mbsf, the first occurrence of biogenous silica. Above $340 \mathrm{mbsf}$, the biogenous component consists of both siliceous and calcareous microfossils. The appearance of the siliceous microfossils probably causes the sudden jump in porosity at 340 mbsf. Further, continued variation in siliceous microfossil content probably dominates porosity fluctuation above this level. In addition, the positive correlation between porosity and biogenous component probably reflects this siliceous influence. In contrast, both gamma-ray and clay content are negatively correlated with porosity for this interval. This inverse pattern is the opposite of the normal pattern of higher clay content causing high porosity. 
Clearly, the variation of siliceous microfossils must be obscuring the normal effect of clay on porosity.

In the lower portion of the upper interval (340-419 mbsf), porosity fluctuations exhibit a gradual upward increase in magnitude, peaking at 382-358 mbsf, then decreasing again for the final $19 \mathrm{~m}$ before the 340 -mbsf transition. The porosity-minima baseline is relatively constant for $419-357$ mbsf, then increases at an accelerating rate as the 340 -mbsf transition is approached. In contrast, the porosity peaks are more variable and do not indicate a simple baseline, except perhaps for $410-389$ mbsf. If the porosity fluctuations for $340-419$ mbsf are caused by changes in clay content, then maximum clay contents vary more from cycle to cycle than do minimum clay contents.

The data suggest, but do not firmly establish, that fluctuations in clay content cause the cyclical porosity variations in the interval from 340 to 419 mbsf. The correlation coefficient of porosity with calculated clay is not shown, but it is positive in this interval. Visual examination of Figure 10 can readily verify this correlation of porosity peaks with clay maxima. However, the correlation coefficient of porosity vs. gamma ray is negative for this interval, possibly because potassium feldspar, rather than clay, is dominating gamma-ray response for this interval. The biogenous component, which smear slides indicate is entirely calcite and almost entirely nannoplankton, can be positively correlated with porosity (Figs. 9 and 10). The simplest explanation is that porosity fluctuations in this interval are caused by fluctuations in strength of bottom currents. During times of weaker currents, fine-grained clay minerals and nannoplankton accumulated, and relatively small amounts of coarser-grained quartz and feldspar are carried to the site. Consequently, porosity is relatively high. During times of stronger currents, the current intensity retards deposition of clay and nannoplankton; relatively more quartz and feldspar are deposited, but our data cannot determine whether the stronger currents cause an absolute increase in the accumulation rate of the coarser-grained minerals. The lack of a high-porosity baseline for the interval suggests that enough bottom-current activity always exists to have some influence on the sediment grain-size distribution. Alternatively, variations in calcite component may affect the magnitude of the porosity maxima and prevent development of a baseline.

Bottom currents also are probably the dominant cause of porosity fluctuations in the lower interval (Fig. 11, 420-732 mbsf), based on similar but more compelling evidence. Calcite abundance can be positively correlated with porosity throughout the interval, and gamma ray also is positively correlated, except for short intervals at about 465-485, 640-680, and 720-730 mbsf. Apparently, clay content dominates the gamma-ray response throughout most of the interval, in contrast to a more significant effect from potassium feldspar higher in the section. We are reluctant to place much confidence in the potassium feldspar log from inversion, in view of the X-ray diffraction indications that nearly all of the feldspar at this site is calcisodic (Cremer and LaTouche, this volume). We note that if the possible presence of potassium feldspar is omitted from the inversion, clay and biogenous components are virtually unaffected; all of the potassium feldspar of Figure $11 \mathrm{can}$ be partitioned into the component quartz plus plagioclase.

Fluctuating bottom-current activity accounts for the correlations of porosity variations with other variables throughout the lower interval. Again, decreased current activity permits more deposition of clays and nannoplankton relative to coarser-grained quartz and plagioclase. Conversely, increased currents selectively winnow the fine fraction, leaving a sediment dominated by coarser quartz and feldspar. With one notable exception, the fluctuations appear to be constant throughout the interval from 420 to 590 mbsf: high- and low-porosity baselines are rather smooth, with fairly constant peak-to-trough amplitudes. The exception is a significant baseline shift at $478-482 \mathrm{mbsf}$. The gradual compaction trend is interrupted here by a decrease in porosity uphole of $2 \%$, associated with a decrease in clay content of $5 \%-10 \%$. This agrees with the grain-size data of Cremer and LaTouche (this volume), which indicate an increase in median grain size at about this depth. This abrupt change probably indicates a sudden strengthening of bottom-current activity. Perhaps fortuitously, the low-porosity baseline below this depth is continuous with the high-porosity baseline above this depth. Further, the regular 9-m cyclicity just below 478-482 mbsf continues above, but apparently with a $180^{\circ}$ phase change. The simplest explanation for these two observations is that the high bottom-current baseline continues unchanged across the 478- to 482 -mbsf transition, and the formerly low-current baseline condition changes suddenly to a high-current environment. The decrease in porosity at $478-482$ mbsf causes a decrease in velocity (Figs. 3 and 7) and, therefore, probably causes a regional seismic reflector (Arthur et al., this volume).

The log-based interpretations of the history of bottom-current activity at Site 646 are consistent with the interpreted sequence of deep circulation events (Arthur et al., this volume), based primarily on seismic stratigraphy. Seismic reflector R2, which marks the earliest Pliocene onset of drift buildup on Eirik Ridge, occurs at about 500 mbsf at Site 646, near the de-

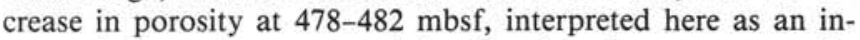
crease in bottom-current activity. Based on log responses, the variability of bottom-current activity did not change substantially at this point. A further intensification of bottom currents began at about 4.1 to $4.2 \mathrm{Ma}$ (391 mbsf), at the base of seismic unit 2 (Shipboard Scientific Party, 1987b). Seismic unit 2, which represents the major sediment-drift buildup on Eirik Ridge, is characterized at Site 646 by several indicators of increased current fluctuations: (1) more variability in median grain size (Cremer and LaTouche, this volume), (2) more variability in carbonate content (Fig. 12), and (3) increased amplitudes of porosity variations (Fig. 3). Sculpting of drifts began at about $3.4 \mathrm{Ma}$ ( $340 \mathrm{mbsf}$ ), in concert with higher sedimentation rates, a major decrease in carbonate deposition, and onset of substantial deposition of opal. These changes at $340 \mathrm{mbsf}$ may imply a decrease in bottom-current velocities, but the sedimentary response to bottom currents is complicated at this depth by productivity changes in surface waters.

Superimposed on these long-term variations in bottom-current activity is an orbitally induced high-frequency variation. Spectral analysis of downhole logs indicates that the dominant high-frequency variations have periods similar to those of eccentricity and obliquity. Obliquity and eccentricity parameters possibly are the most important because of their potential control on production of Norwegian Sea Overflow Water, which presumably is the main deep-water mass in this region over at least the last 8 m.y. However, Kellogg (1987) expressed reservations about drawing such conclusions on the basis of currently available data, and detailed evaluation of the potentially complex orbital forcing of high-latitude sedimentary cycles (Fig. 13) is beyond the scope of this study.

\section{CONCLUSIONS}

The examination of downhole geophysical logs over intervals of Sites 645 and 646 reveals pronounced cyclicity, particularly in sonic and resistivity records. Porosity variation is the most significant geological cause of this cyclic log behavior at both sites. The porosity variation largely reflects cyclic changes in the relative amount of clay minerals and coarser-grained mineral phases; it is paralleled to some extent by variations in gamma-ray and spectral-gamma records. Spectral analysis of the logging records suggests cycle frequencies that closely correspond to predicted 


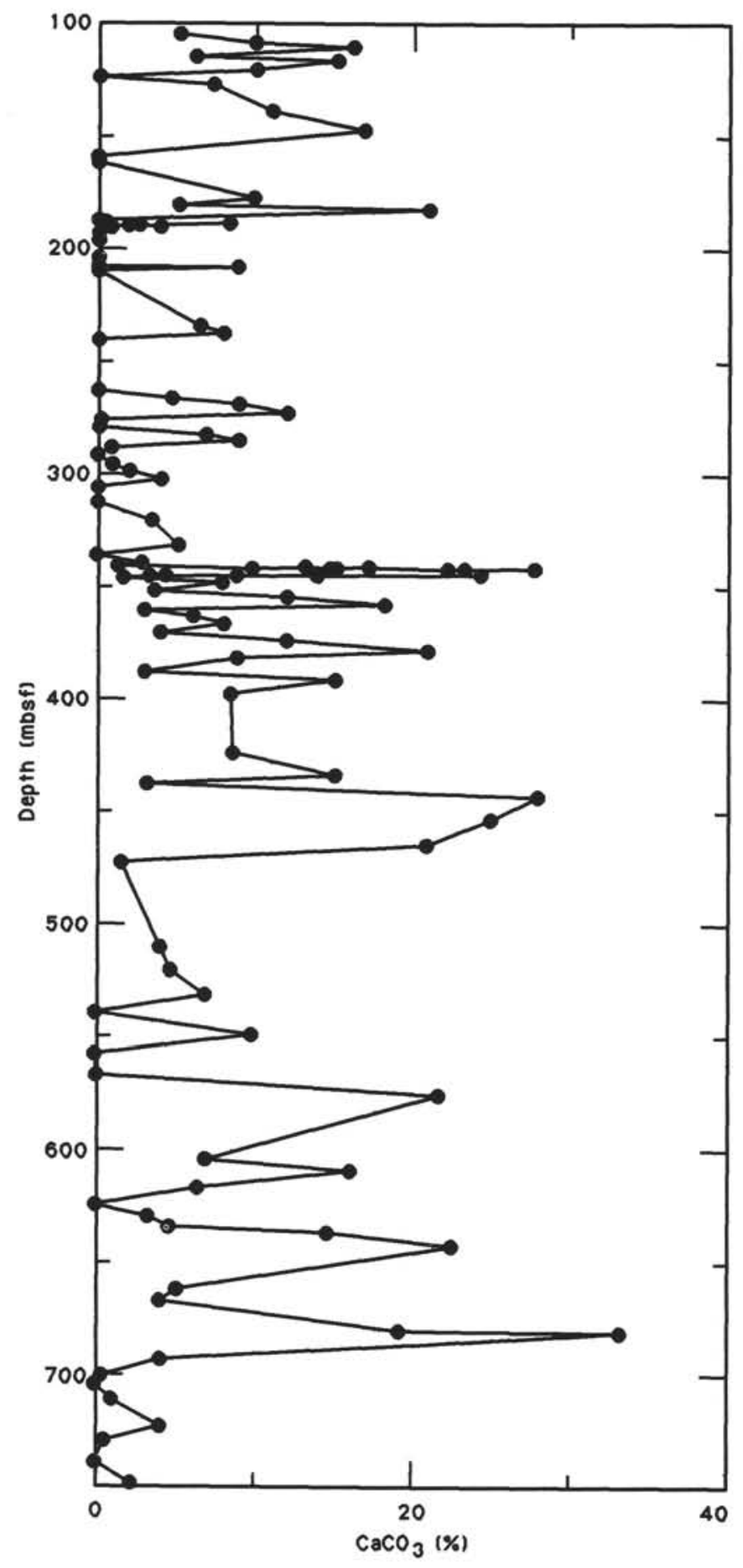

Figure 12. Total percentage of calcium carbonate for Site 646 from 100 mbsf to 750 mbsf, based on shipboard core analyses, supplemented by data collected for this study. Core recovery limited sampling of many intervals.

periodicities of Milankovitch orbital parameters, i.e., about 40 and 100 k.y., near that of the major obliquity and eccentricity terms. Significant spectral power in the precessional band (average 21 k.y.) was found only in part of the Site 645 record, where sedimentation rates were sufficiently high to resolve them. Although variance in that band was not detected at Site 646, even in intervals of high sedimentation rate, we cannot be certain that cycles with periodicities corresponding to precessional variations are not present. Further, we cannot exclude the possibility that much of the detected energy in the eccentricity band results from the sedimentary response to eccentricity-modulated precessional climatic changes.

Most likely, the dominant log cycles at both sites were produced by variations in intensity of bottom-water circulation, with superimposed variations in flux of ice-rafted debris at Site 645 (Fig. 13). The cycles in porosity and interval transit time are dominantly a function of clay content, with highest clay content and highest porosity interpreted as times of lower bottom-current velocities. Bottom-current intensity appears to have been modulated by obliquity, but as is characteristic of spectra of oxygen-isotope and carbonate data from Quaternary records, the variance in the eccentricity band is very high. This may reflect climatically induced variations in productivity throughout the record (carbonate and opal content), as well as variations in flux of ice-rafted debris after about 3.2 Ma at Site 645 and $2.5 \mathrm{Ma}$ at Site 646.

Because of the relatively poor core recovery in parts of both sites, the downhole logs are invaluable for detecting and understanding the possible modulation of sedimentation by Milankovitch-induced variations in climate, fluxes of ice-rafted debris, surface-water productivity, and deep-water circulation intensity at these sites. Use of spectral characteristics of the logs may help to refine sedimentation rates and, therefore, sediment fluxes and event stratigraphy for narrower intervals of the sequence in which biostratigraphic or magnetostratigraphic data are inadequate. However, this will depend on better knowledge of the potential variations in periodicity of the orbital parameters farther back in time.

We recommend logging of pelagic-hemipelagic sequences for future studies of Milankovitch cycles. Although the vertical resolution of each type of logging tool varies (e.g., about $0.6 \mathrm{~m}$ for some, $1 \mathrm{~m}$ for resistivity), downhole logs are useful today for cycle resolution in sequences that were deposited at rates of greater than about $30 \mathrm{~m} / \mathrm{m}$.y. Because of problems with aliasing, the full range of potential Milankovitch cycles (19 k.y. and up) can be resolved only at sedimentation rates of about $100 \mathrm{~m} / \mathrm{m}$.y.

\section{ACKNOWLEDGMENTS}

We thank the Shipboard Scientific Party of Leg 105 for the cooperative scientific effort that made this project possible. Financial support was provided by USSAC grants TAMRF76286 and TAMRF76322.

\section{REFERENCES}

Arthur, M. A., Dean, W. E., Bottjer, D., and Scholle, P. A., 1984. Rhythmic bedding in Mesozoic-Cenozoic pelagic carbonate sequences: the primary and diagenetic origin of Milankovitch-like cycles. In Berger, A., Imbrie, J., Hays, J., Kukla, G., and Saltzman, B. (Eds.), Milankovitch and Climate, Vol. 1: Dordrecht/Boston/ Lancaster (Reidel), 191-222.

Berggren, W. A., Kent, D. V., and Van Couvering, J. A., 1985. Neogene geochronology and chronostratigraphy. In Snelling, N. J. (Ed.), Geochronology and the Geologic Time Scale. Geol. Soc. (London) Mem., $10: 211-250$

Doveton, J. H., 1986. Log Analysis of Subsurface Geology: Concepts and Computer Methods: New York (John Wiley \& Sons).

Fischer, A. G., 1986. Climatic rhythms recorded in strata. Annu. Rev. Earth Planet. Sci., 14:351-376.

Fischer, A. G., and Schwarzacher, W., 1984. Cretaceous bedding rhythms under orbital control? In Berger, A., Imbrie, J., Hayes, J., Kukla, G., and Saltzman, B. (Eds.), Milankovitch and Climate, Vol. 1: Dordrecht/Boston/Lancaster (Reidel), 163-175.

Gassmann, F., 1951. Elastic waves through a packing of spheres. Geophysics, 26:673-685.

Hays, J. D., Imbrie, J., and Shackleton, N. J., 1976. Variations in the Earth's orbit: pacemaker of the ice ages. Science, 194:1121-1132.

Imbrie, J., Hays, J. D., Martinson, D. G., McIntyre, A., and Mix, A. C., 1984. The orbital theory of Pleistocene climate: support from a re- 
vised chronology of the marine $\delta^{18} \mathrm{O}$ record. In Berger, A., Imbrie, J., Hays, J., Kukla, G., and Saltzman, B. (Eds.), Milankovitch and Climate, Vol. 1: Dordrecht/Boston/Lancaster (Reidel), 269-306.

Kellogg, T. B., 1987. Glacial-interglacial changes in global deepwater circulation. Paleoceanography, 2:259-271.

Olsen, P. E., 1986. A 40-million-year lake record of early Mesozoic climatic forcing. Science, 234:842-848.

Ruddiman, W. F., Raymo, M., and McIntyre, A., 1986. Matuyama 41,000-year cycles: North Atlantic Ocean and Northern Hemisphere ice sheets. Earth Planet. Sci. Lett., 80:117-129.
Srivastava, S. P., Arthur, M. A., et al., 1987a. Proc. ODP, Init. Repts., 105: College Station, TX (Ocean Drilling Program), 61-418.

Srivastava, S. P., Arthur, M. A., et al., 1987b. Proc. ODP, Init. Repts.,105: College Station, TX (Ocean Drilling Program), 419-674.

Srivastava, S. P., Arthur, M. A., et al., 1987c. Proc. ODP, Init. Repts., 105: College Station, TX (Ocean Drilling Program), 675-905.

Date of initial receipt: 6 April 1988

Date of acceptance: 29 September 1988

Ms 105B-151

\section{FORCING OF CYCLICITY AT HIGH LATITUDE \\ LABRADOR SEA - BAFFIN BAY SITES}

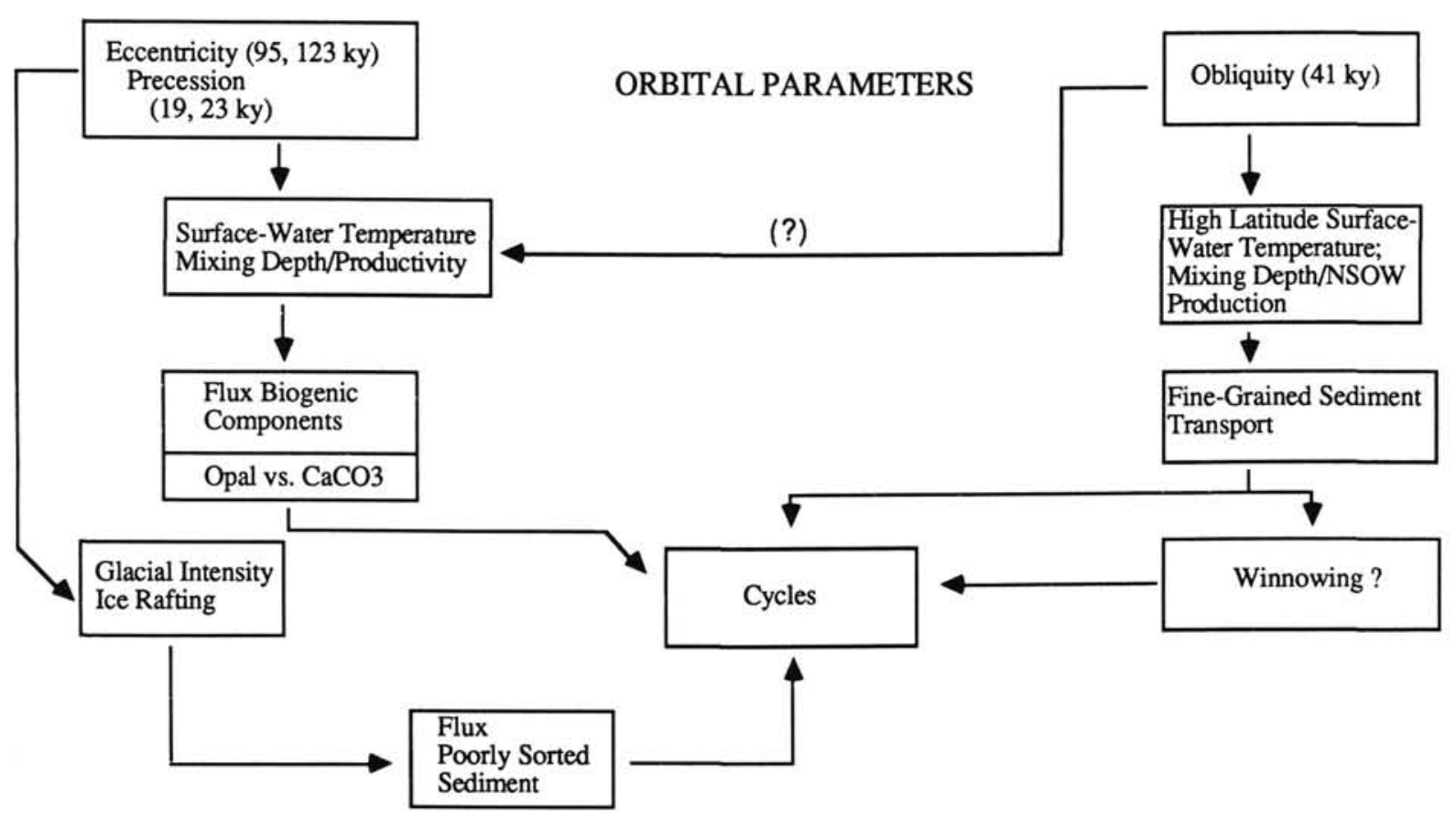

Figure 13. Suggested influence of orbital parameters on sedimentation at Site 646 . 